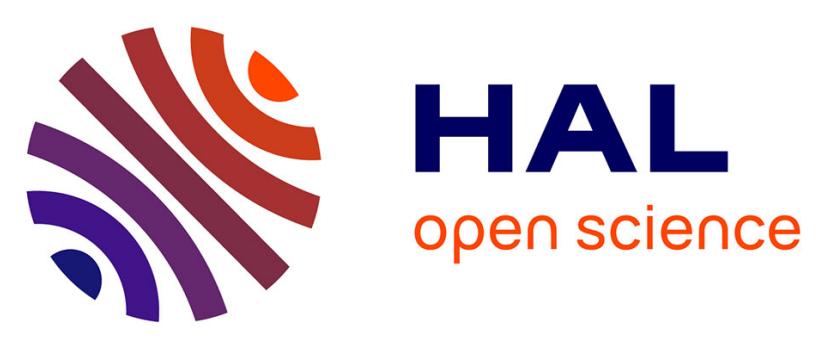

\title{
Mutant SOD1 and mitochondrial damage alter expression and splicing of genes controlling neuritogenesis in models of neurodegeneration
}

Silvia Carolina Lenzken, Valentina Romeo, Francesca Zolezzi, Francesca Cordero, Giuseppe Lamorte, Davide Bonanno, Donatella Biancolini, Mauro Cozzolino, Maria Grazia Pesaresi, Alessia Maracchioni, et al.

\section{To cite this version:}

Silvia Carolina Lenzken, Valentina Romeo, Francesca Zolezzi, Francesca Cordero, Giuseppe Lamorte, et al.. Mutant SOD1 and mitochondrial damage alter expression and splicing of genes controlling neuritogenesis in models of neurodegeneration. Human Mutation, 2011, 32 (2), pp.168. 10.1002/humu.21394 . hal-00610796

\section{HAL Id: hal-00610796 https://hal.science/hal-00610796}

Submitted on 25 Jul 2011

HAL is a multi-disciplinary open access archive for the deposit and dissemination of scientific research documents, whether they are published or not. The documents may come from teaching and research institutions in France or abroad, or from public or private research centers.
L'archive ouverte pluridisciplinaire HAL, est destinée au dépôt et à la diffusion de documents scientifiques de niveau recherche, publiés ou non, émanant des établissements d'enseignement et de recherche français ou étrangers, des laboratoires publics ou privés. 


\section{Human Mutation}

WILEY

\section{Mutant SOD1 and mitochondrial damage alter expression and splicing of genes controlling neuritogenesis in models of neurodegeneration}

\begin{tabular}{|c|c|}
\hline Journal: & Human Mutation \\
\hline Manuscript ID: & humu-2010-0331.R1 \\
\hline Wiley - Manuscript type: & Research Article \\
\hline $\begin{array}{l}\text { Date Submitted by the } \\
\text { Author: }\end{array}$ & 15-Sep-2010 \\
\hline Complete List of Authors: & $\begin{array}{l}\text { Lenzken, Silvia; University of Milano-Bicocca, Department of } \\
\text { Biotechnology and Biosciences } \\
\text { Romeo, Valentina; University of Milano-Bicocca, Department of } \\
\text { Biotechnology and Biosciences } \\
\text { Zolezzi, Francesca; Genopolis Consortium, University of Milano- } \\
\text { Bicocca, Department of Biotechnology and Biosciences } \\
\text { Cordero, Francesca; University of Torino, Department of Clinical } \\
\text { and Biological Sciences } \\
\text { Lamorte, Giuseppe; University of Milano-Bicocca, Department of } \\
\text { Biotechnology and Biosciences } \\
\text { Bonanno, Davide; University of Milano-Bicocca, Department of } \\
\text { Biotechnology and Biosciences } \\
\text { Biancolini, Donatella; Genopolis Consortium, University of Milano- } \\
\text { Bicocca, Department of Biotechnology and Biosciences } \\
\text { Cozzolino, Mauro; Fondazione Santa Lucia, IRCCS } \\
\text { Pesaresi, Maria; Fondazione Santa Lucia, IRCCS; University of } \\
\text { Rome "Tor Vergata, Department of Biology } \\
\text { Maracchioni, Alessia; Fondazione Santa Lucia, IRCCS } \\
\text { Sanges, Remo; CBM scrl - Genomics } \\
\text { Achsel, Tilmann; Katholieke Universiteit, VIB, Department of } \\
\text { Molecular and Developmental Genetics; Fondazione Santa Lucia, } \\
\text { IRCCS } \\
\text { Carrì, Maria; University of Rome "Tor Vergata, Department of } \\
\text { Biology; Fondazione Santa Lucia, IRCCS } \\
\text { Calogero, Raffaele; University of Torino, Department of Clinical and } \\
\text { Biological Sciences } \\
\text { Barabino, Silvia; Università di Milano-Bicocca, Biotechnology and } \\
\text { Biosciences }\end{array}$ \\
\hline Key Words: & $\begin{array}{l}\text { ALS, axon guidance, microarray, mitochondria, neurodegeneration, } \\
\text { RNA splicing, SOD1 }\end{array}$ \\
\hline
\end{tabular}






\section{SCHOLARONE ${ }^{m}$ Manuscripts}

25

26

27

29

32

33

34

35

36

37

39

40

41

42

44

45

46

47

48

49

50

52

53

54

56

57

58

60

John Wiley \& Sons, Inc. 


\title{
Mutant SOD1 and mitochondrial damage alter expression and splicing of genes
} controlling neuritogenesis in models of neurodegeneration

\author{
Silvia C. Lenzken ${ }^{1}$, Valentina Romeo ${ }^{1}$, Francesca Zolezzi ${ }^{2}$, Francesca Cordero ${ }^{3}$, \\ Giuseppe Lamorte ${ }^{1}$, Davide Bonanno ${ }^{1}$, Donatella Biancolini ${ }^{2}$, Mauro Cozzolino ${ }^{6}$, \\ Maria Grazia Pesaresi ${ }^{6}$, Alessia Maracchioni ${ }^{6}$, Remo Sanges $^{7}$, Tilmann Achsel ${ }^{4,6}$, \\ Maria Teresa Carri ${ }^{5,6}$, Raffaele A. Calogero ${ }^{3}$, and Silvia M.L. Barabino ${ }^{1 *}$
}

${ }^{1}$ Department of Biotechnology and Biosciences, University of Milano-Bicocca, Piazza della Scienza, 2, 20126 Milano, Italy

${ }^{2}$ Genopolis Consortium, University of Milano-Bicocca, Piazza della Scienza 2-4, 20126 Milano, Italy

${ }^{3}$ Department of Clinical and Biological Sciences, University of Torino, Regione Gonzole 10, Orbassano, 10043, Torino, Italy

${ }^{4}$ VIB Department of Molecular and Developmental Genetics, KU Leuven, Belgium

${ }^{5}$ Department of Biology, University of Rome “Tor Vergata," Rome, Italy.

${ }^{6}$ Laboratory of Neurochemistry, Fondazione Santa Lucia, IRCCS, Rome, Italy.

${ }^{7}$ CBM scrl - Genomics, Area Science Park, Basovizza, Trieste, Italy

Running title: Alternative splicing and neurodegeneration

Keywords: ALS, axon guidance, microarray, mitochondria, neurodegeneration, RNA splicing, SOD1

*Corresponding author: Silvia M.L. Barabino 
Department of Biotechnology and Biosciences

University of Milano-Bicocca, Piazza della Scienza, 2

I-20126 Milano, Italy;

Phone: +39-02-6448 3352

Fax: +39-02-6448 3569

E-mail: silvia.barabino@unimib.it 


\section{Abstract}

Mitochondrial dysfunction has been implicated in the pathogenesis of a number of neurodegenerative disorders including Parkinson, Alzheimer and Amyotrophic Deleted: 's disease

Lateral Sclerosis (ALS). In addition, aberrant mRNA splicing has been documented in neurodegeneration. To characterize the cellular response to mitochondrial perturbations at the level of gene expression and alternative pre-mRNA splicing we used splicing-sensitive microarrays to profile human neuroblastoma SH-SY5Y cells treated with paraquat, a neurotoxic herbicide that induces the formation of reactive oxygen species and causes mitochondrial damage in animal models, and SH-SY5Y cells stably expressing the mutant G93A-SOD1 protein, one of the genetic causes of ALS. In both models we identified a common set of genes whose expression and alternative splicing are deregulated. Pathway analysis of the deregulated genes revealed enrichment in genes involved in neuritogenesis, axon growth and guidance, and synaptogenesis. Alterations in transcription and pre-mRNA splicing of candidate genes were confirmed experimentally in the cell line models as well as in brain and spinal cord of transgenic mice carrying the G93A-SOD1 mutation. Our findings expand the realm of the pathways implicated in neurodegeneration and suggest that alterations of axonal function may descend directly from mitochondrial damage. 


\section{Introduction}

Mitochondrial dysfunction has been directly or indirectly implicated in the pathogenesis of a number of neurodegenerative disorders including Parkinson, Alzheimer and Huntington (Gibson, et al., 2009). In recent years, mitochondrial damage has also emerged as an early factor contributing to the pathogenesis of Amyotrophic Lateral Sclerosis (ALS, Magrane and Manfredi, 2009).

ALS is a progressive, invariably fatal, neurodegenerative disease caused by the degeneration of motor neurons (Boillee, et al., 2006). Sporadic ALS (sALS) is a genetically and clinically very heterogeneous disease (Chio, et al., 2009). The aetiology of sALS is largely unknown but is likely linked to both environmental and genetic factors inducing mechanisms of motor neuron damage. These mechanisms include oxidative damage, accumulation of intracellular aggregates, mitochondrial failure, defects in axonal transport, growth factor deficiency, aberrant RNA metabolism, glial cell pathology, and glutamate excitotoxicity (Cozzolino, et al., 2008; Rothstein, 2009). Familial ALS (fALS) accounts for approximately 5\%-10\% of all ALS cases and is caused by genetic factors. Of these, approximately 1 in 5 are linked to a mutation in copper/zinc superoxide dismutase 1 (SOD1,\#MIM 147450), an enzyme responsible for scavenging the free $\mathrm{O}_{2}{ }^{-}$radicals.

There is a substantial body of evidence indicating that mitochondrial dysfunction is a feature of motor neuron degeneration in ALS. Mitochondrial damage has been reported both in sporadic and familial ALS patients and in cellular and animal models that express mutant SOD1 (Shi, et al., 2010). Mitochondrial dysfunction may lead to the degeneration of motor neurons because of energy deprivation following impairment of the respiratory chain, alteration of intracellular calcium handling and activation of the apoptotic pathway. We have recently reported that mitochondrial 
dysfunction caused by paraquat (N,N'-dimethyl-4,4'-bipyridinium dichloride, $\mathrm{PQ}$ ), a neurotoxic herbicide that induces Parkinsonian features in animal models, has another, quite unexpected effect, i.e. it modulates alternative splicing of a set of mRNAs in cells of neuronal origin (Maracchioni, et al., 2007). The importance of alternative splicing (AS) in regulating gene expression is illustrated by a growing number of diseases associated with abnormal mRNA patterns (for review see (Cooper, et al., 2009). Alterations of the splicing pattern of several mRNAs have been reported in ALS patients and in murine models (Aerbajinai, et al., 2002; Munch, et al., 2002; Pantelidou, et al., 2007; Robertson, et al., 2003; Tomiyama, et al., 2002). Recently, the identification in fALS patients of mutations in TARDBP (MIM\# 605068) and FUS (MIM\# 13070) that encode DNA/RNA-binding proteins has further strengthened the idea that splicing abnormalities may contribute to neurodegeneration (Lagier-Tourenne and Cleveland, 2009).

Based on these reports, we hypothesized that not only gene expression but also alternative pre-mRNA splicing might be altered in neurodegenerative conditions involving mitochondrial damage such as ALS, or Parkinson's disease. We thus performed a whole-genome, exon level analysis of the cellular response to mitochondrial failure. Using Affimetrix Exon 1.0 ST GeneChips ${ }^{\circledR}$ microarrays we profiled human neuroblastoma SH-SY5Y cells treated with PQ, and SH-SY5Y cells stably expressing the mutant G93A-SOD1protein, which is one of the genetic causes of ALS. We then combined the data sets from the two experiments to identify common molecular pathways underlying the response to mitochondrial insufficiency. The results revealed alterations in the transcriptional and post-transcriptional expression of several genes involved in neuritogenesis and support a role for the 
alteration in axon growth and guidance molecules as a partner in mitochondriamediated neurodegeneration.

\section{Materials and Methods}

\section{Cell culture}

Human neuroblastoma SH-SY5Y untransfected or stably transfected with cDNAs coding for wild type SOD1 or the mutant G93A-SOD1 (Carri, et al., 1997), were cultured in D-MEM/F-12 media with GlutaMAX ${ }^{\mathrm{TM}}$ (Gibco, Invitrogen, UK), 10\%

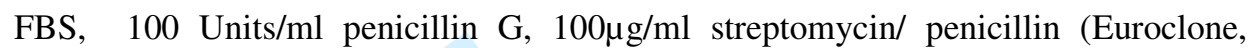
Milano, Italy). Stably transfected cells were also maintained in the presence of $400 \mu \mathrm{g} / \mathrm{ml}$ Geneticin (G418 sulphate, Euroclone). Cells were fed every 2-3 days and passed once a week. For the microarray experiment, after an initial amplification of each cell type, cells were aliquoted and stored in liquid nitrogen. For every experiment an aliquot of each cell line was thawed and seeded. After having reached confluence, cells were reseeded at $3 \times 10^{6}$ cells in $100 \mathrm{~mm}$ dish. Paraquat (N,N'dimethyl-4,4'-bipyridinium dichloride, Sigma-Aldrich) treatment was carried out essentially as described in (Maracchioni, et al., 2007) but for $18 \mathrm{~h}$ at $0,75 \mathrm{mM}$ concentration.

\section{RNA preparation}

Total RNA was from cultured cells extracted using TRIzol® Reagent (Invitrogen), and subsequently purified using silica membrane spin columns from RNeasy Mini kit (Qiagen). RNA quantity and purity were assessed using a NanoDrop® instrument (Thermo Fisher Scientific Inc.). Total RNA integrity was assessed by using a 2100 Bioanalyzer (Agilent Technologies) and the RNA Integrity Number (RIN) was 
calculated. Mouse total RNA was isolated from brain and spinal cord with TRIzol® Reagent (Invitrogen) from eleven healthy female mice (controls) and fourteen female G93A-SOD1mice sacrificed between 93 and 170 days.

\section{Microarray hybridization and data analysis}

Each condition was replicated 5 times. After extraction and quality check $1.5 \mu \mathrm{g}$ of total RNA was subjected to removal of ribosomal RNA following the procedure suggested by the manufacturer (Affymetrix). The resulting total RNA was then used to created the biotin-labelled library to be hybridized on GeneChip® Exon 1.0 ST human microarrays following the procedure described by the manufacturer (Affymetrix). The CEL files resulting from the hybridization were analyzed using oneChannelGUI 1.6.5 (Sanges, et al., 2007). Gene-level calculation was performed by RMA (Robust Multichip Average, (Irizarry, et al., 2003) and normalization by quantile sketch (Bolstad, et al., 2003). To assess differential expression at gene-level, we used an empirical Bayes method (Smyth, 2004) together with a false discovery rate (FDR) correction of the p-value (Westfall PH, 1993). Thus, the list of differentially expressed genes was generated using an FDR $\leq 0.05$ together with an absolute $\log _{2}$ (fold-change) threshold of 1 . Differential expression was detected by linear model statistics. This method is based on the fitting of a linear model to estimate the variability in the data. In case of one-channel microarray data this approach is the same as the analysis of variance except that a model is fitted for every gene. For the detection of the differential expression an empirical Bayes method is used to moderate the standard errors. The use of moderated statistics for the detection of differential expression is especially useful in cases of experiments with a small number of replicates. 
1

2

3

4

5

6

7

8

9

10

11

12

13

14

Alternative splicing events (ASEs) were detected as described in (Della Beffa, et al., 2008). Briefly, an intensity filter was applied at gene-level to remove not expressed and low expressed genes, i.e. genes were retained for exon-level analysis if in all biological replication gene-level signal was greater than 5 . Subsequently, only genes characterized to have at least two RNA isoforms annotated in Ensembl database (Ensembl 56 release, September 2009, (Flicek, et al., 2008)) were retained for further analysis. The Splicing Index value was calculated by taking the $\log _{2}$ ratio of the normalized exon intensity (NI) in Sample 1 and the NI in Sample 2. The normalized exon intensity (NI) is the ratio of the probe set intensity to the gene intensity.

The data discussed in this publication have been deposited in the NCBI Gene Expression Omnibus (Edgar, et al., 2002) and are accessible through GEO Series accession number GSE21450 embedding dataset SOD1 (GSE21298) and dataset PQ (GSE21305).

\section{Quantitative RT-PCR assays}

For the experiments performed on cultured cells, the relative mRNA levels of selected transcripts were determined by qPCR on three biological replicates and a pool of the same RNA samples employed for the microarray experiments. $2 \mu \mathrm{g}$ of total RNA were reverse-transcribed using MultiScriveTM Reverse Transcriptase (Applied Biosystems), random hexamers (Applied Biosystems), RNAsin Plus reagent (Promega) and dNTPs for $2 \mathrm{~h}$ at $37^{\circ} \mathrm{C}$ according to manufacture's instruction. qPCR amplifications were performed in a final volume of $25 \mu 1$ with SYBR ${ }^{\circledR}$ Green qPCR master mix (Applied Biosystems), $1 \mu \mathrm{l}$ cDNA diluted (1:50), and $0.2 \mu \mathrm{M}$ of each primer (for sequences see Supporting Material, Table S8 “Oligonucleotide primers"). 
Amplifications were performed in duplicate or triplicate using an ABI PRISM 7500 real time system (Applied Biosystems). The amplification protocol was as follows: an initial denaturation and activation step at $95^{\circ} \mathrm{C}$ for $10 \mathrm{~min}$, followed by 40 cycles of $95^{\circ} \mathrm{C}$ for $15 \mathrm{~s}$ and $60^{\circ} \mathrm{C}$ for $1 \mathrm{~min}$. After the amplification phase, a dissociation step was carried out at $95^{\circ} \mathrm{C}$ for $15 \mathrm{~s}, 60^{\circ} \mathrm{C}$ for $1 \mathrm{~min}$, and $95^{\circ} \mathrm{C}$ for $15 \mathrm{~s}$. For normalization of cDNA loading, all samples were run in parallel using GAPDH as housekeeping gene for human samples and Hprt1 for mouse samples. To estimate primer efficiencies, a standard curve was generated for each primer pair from 10-fold serial dilutions (from 20 to $0.002 \mathrm{ng}$ ) of a pool of first-stranded cDNA template from all samples. Standard curves represented the cycle threshold $(\mathrm{Ct})$ value as a function of the logarithm of the number of copies generated. All real-time PCR efficiencies were above $85 \%$. Values of relative expression in neuroblastoma cells [(treated with PQ vs. untreated or G93A-SOD1 vs. WT-SOD1] or mouse tissues (brain or spinal cord from transgenic vs. control) were statistically analyzed by two tailed t-test.

The data of the expression analysis on mouse spinal RNA during disease progression was analyzed using a linear regression model and plotted as deltaCt(transcript-Hprt1) vs. age. Statistical analysis was performed using SPSS software (SPSS Inc.). Wasf3 and Sept2 expression data were grouped into different stages (pre-onset: 93, 103, and 113 days; onset: 135 days; symptomatic stage: 140 - 170 days) and plotted as $1 / 2^{\wedge} \operatorname{deltaCt}($ transcript-Hprt1) vs. phases (pre-onset phase: Ntg: $n=6$, G93A: $n=5$; early phase Ntg: n=2, G93A: $n=2$; symptomatic phase: Ntg: $n=3$; G93A: $n=7$ ).

Alternative splicing events validation by RT-PCR
Validation of splicing changes predicted by microarray experiments was performed
by RT-PCR analysis on a pool of the RNA samples used for array hybridization and 
1

2

3

4

5

6

7

8

9

10

11

12

13

14

on 3 other independent preparations. cDNA synthesis was performed as described above. Assay conditions were optimized for each gene with respect to primer annealing temperatures, primer concentration, and $\mathrm{MgCl} 2$ concentrations. The number of amplification cycles used for each reaction was determined to ensure that transcript amplification was within a linear range (25 to 35 cycles). Gene specific primer sequences are listed in Supporting Material, Table S8. PCR products were separated by electrophoresis on 2-4\% agarose gels. Quantification was performed with a 2100 Bioanalyzer (Agilent Technologies). Statistical analysis was performed using GraphPad Instat software (GraphPad Software Inc.). The amplified PCR products were cloned in pGEM T Easy Vector System (Promega, Madison, USA) and sequenced by BMR Genomics.

\section{Immunoblotting}

Cell monolayers were washed twice with ice cold PBS and lysed on the tissue culture dish by addition of ice-cold lysis buffer $(50 \mathrm{mM}$ Tris- $\mathrm{HCl}$, pH 7.5, 150mM NaCl, and 1\% NP-40, and complete protease inhibitor cocktail (Roche Diagnostics). The samples were then centrifuged at $15,000 \mathrm{rcf}$ for $15 \mathrm{~min}$ at $4^{\circ} \mathrm{C}$, and the supernatants were collected. An aliquot of the cell lysate was used for protein analysis with the Bio-Rad Bradford kit for protein quantification. Proteins were subjected to SDSPAGE and then transferred onto nitrocellulose membrane (Thermo Fisher Scientific). The membranes was blocked for $1 \mathrm{~h}$ with $5 \%$ non-fat dry milk in PBS-buffered saline containing 1\% Tween 20 (PBS-T). Membranes were immunoblotted with antibodies of interest for $1 \mathrm{~h}$. Anti-cyclin A, and anti-cyclin B, were from BD Biosciences, (Pharmingen). The anti-NTRK1 (TrkA) antibody was from Abcam. 
For the analysis of semaphorin $3 \mathrm{~A}$ expression, $10^{6}$ cells were plated on $60 \mathrm{~mm}$ Petri dishes. After $24 \mathrm{hrs}$ culture in normal growth medium, cells were shifted in $3 \mathrm{ml}$ OPTIMEM (Invitrogen) and cultured for 18hrs. Supernatants were harvested, centrifuged to remove cell debris, and $200 \mathrm{ml}$ of cleared supernatants were precipitated with 6 volumes of a 2:1:1 Ethanol/Methanol/Acetone mix and resuspended in Laemmli sample buffer. Equal volumes were subjected to SDS-PAGE and analysed in Western blot with an anti-SEMA3A mouse monoclonal antibody (Santa Cruz Biotechnology Inc.). To normalize the amounts of secreted SEMA3A to the cell number, cells were lysed in RIPA buffer and equivalent amounts of protein extracts were analysed in Western blot with a mouse monoclonal anti-b-actin antibody (Sigma-Aldrich).

The detection was carried out by incubation with horseradish peroxidase conjugated sheep anti-mouse IgG (Amersham) for $1 \mathrm{~h}$. The blots were then washed extensively and the proteins visualized using an enhanced chemiluminescent detection system (Amersham).

\section{Animals}

Transgenic mice expressing the human SOD1 gene with the G93A mutation (strain B6.Cg-Tg(Sodl-G93A)1Gur=J, Gurney, et al., 1994) were purchased from the Jackson Laboratory (Bar Harbor, ME). Transgenic females were used for RNA extraction and compared to age-matched non-transgenic females. The same operator who was blind to the genotype of mice tested all animals twice a week for deficit in grip strength, Rotarod performance and body weight. The progressive body weight loss was calculated as the difference from the maximum weight recorded for each animal. Analyses started at 30 days (progressive body weight) and 12 weeks (motor 
1

2

3

4

5

6

7

8

9

10

11

12

13

14

15

16

17

18

19

20

21

22

23

24

25

26

27

28

29

30

31

32

33

34

35

36

performances) of age. Rotarod testing was performed using the accelerating Rotarod apparatus (Ugo Basile 7650 model). The onset of clear symptoms was considered when the mice showed the first impairment in grip strength. The symptomatic phase stage of disease was considered when the mice showed a $10 \%$ weight loss that was usually accompanied with the first impairment in Rotarod performance. All animal studies were conducted in accordance with standard ethical guidelines

\section{Results}

The fact that neurons are highly dependent on the oxidative energy metabolism has suggested a common pathogenic mechanism for neurodegeneration based on an underlying dysfunction in mitochondrial activity. To investigate the cellular response to mitochondrial insufficiency both at the level of gene expression and at the premRNA splicing level we performed a whole-genome, splicing-sensitive microarray analysis of two experimental paradigms. First, we profiled untreated human neuroblastoma SH-SY5Y cells vs. cells treated with PQ. PQ is a neurotoxic herbicide that belongs to the class of redox cycling compounds capable of inducing mitochondrial damage, increasing reactive oxygen species (ROS) production and oxidative stress (Birney, et al., 2007; Castello, et al., 2007). For this experiment, the most effective PQ concentration was determined by concentration-response time course studies using an MTT assay to monitor mitochondrial activity, and RT-PCR to verify alternative splicing changes of endogenous transcripts (see Supporting Results). Second, we analyzed SH-SY5Y cells stably expressing wild type SOD1 (WT-SOD1) vs. cells expressing a pathogenic mutation (G93A-SOD1, (Carri, et al., 1997). We have previously demonstrated that this mutant SOD1 induces mitochondrial defects such as depolarization, impaired respiratory activity and ATP production, altered 
calcium buffering and cytochrome c release in this and other neuronal cell lines (Cozzolino, et al., 2009; Ferri, et al., 2006; Jaiswal, et al., 2009). Mitochondrial damage has been repeatedly reported also in transgenic mice overexpressing Sod1G93A (Damiano, et al., 2006; Jaiswal and Keller, 2009; Mattiazzi, et al., 2002; Nguyen, et al., 2009). In this experiment, WT-SOD1 cells were used as a control to rule out unspecific effects due to the transfection and/or to an increased level of SOD1 activity.

After having assessed their quality (see Supporting Material), biologic quintuplicate RNA samples prepared from each experimental paradigm were hybridized to Human Exon 1.0 ST Arrays (Affymetrix), which allow the definition of both transcription patterns (gene-level analysis) and alternative pre-mRNA maturation events (exonlevel analysis). Probesets on the Exon Array are classified as Core, Extended, or Full according to the reliability of the annotation used to define the putative genomic regions of interest. All analyses reported here utilized only the highest confidence "core" probesets, which are based on RefSeq and GenBank full-length mRNAs. Probesets are grouped into "transcript clusters" corresponding to all possible isoforms transcribed from a single locus or gene; therefore, for simplicity we refer to transcript clusters as genes throughout these results. As illustrated in Figure 1A, gene-level and exon-level data sets were generated for each experiment. Hierarchical clustering showed good segregation of treated samples from control samples (PQ vs. untreated and G93A-SOD1 vs. WT-SOD1, respectively (Figure 1B). Sample group homogeneity was also confirmed by Principal Component Analysis (not shown) Differential expression was detected by linear model statistics (see Materials and Methods, (Smyth, 2004)). Exon-level calculation was done by RMA (Irizarry, et al., 2003) and normalization by quantile sketch (Bolstad, et al., 2003). Also in this case 
hierarchical cluster analysis showed a good correlation between the two experimental groups (Figure 1C).

Gene-level expression profiling reveals extensive transcriptional changes upon mitochondrial dysfunction

We first analyzed gene expression changes in PQ-treated cells. To identify differentially expressed genes we applied, as cut off an absolute $\log _{2}$-fold change $\geq \pm 1$ and a p-value $\leq 0.05$. Among the 790 genes that were differentially expressed in the treated samples compared with the controls, 403 were upregulated and 387 were downregulated (Supporting Material, Supp. Table S1 "Paraquat gene-level analysis"). The selected genes were analyzed for their molecular and cellular functions and involved pathways using the Ingenuity Pathways Analysis software (IPA7.0, Ingenuity Systems $\left.{ }^{\circledR}\right)$. The analysis identified Cellular Growth and Proliferation, Cell Death, and Cell Cycle, as the top three categories among the known affected biological functions (Table 1). Consistent with the idea that oxidative stress is a critical mechanism in PQ-induced neurotoxicity (Castello, et al., 2007), IPA 7.0 analysis identified 29 genes that are associated with oxidative stress (Table 2). However, the dominant pathway affected by PQ treatment was p53 signalling. The activation of the p53-mediated response is indicated by the upregulation of ATF3, BTG2, CDKN1A, GADD45A/B/G, MDM2, PPM1D, SESN1/2, TP53INP1, and by POLH (for gene name abbreviations see Supp. Table S8).

Next, we carried out whole-genome profiling of SH-SY5Y cells stably transfected with cDNAs coding for WT-SOD1 or the mutant G93A-SOD1 protein. Among the 192 genes that were found to be differentially expressed in the G93A-SOD1 samples, 81 were upregulated and 111 were down-regulated (Supp. Table S2 "SOD gene-level 
analysis"). Analysis of the selected genes with IPA7.0 identified Cellular Movement as top affected molecular and cellular function, Nervous System Development as top affected function related to "Physiological System Development and Function", and Genetic Disorders, Neurological Diseases and Psychological Diseases as the top three categories among the affected functions related to "Diseases and Disorders" (Table 3).

In order to identify common deregulated pathways, we then combined those genes from the two data sets, which were characterized by an absolute $\log _{2}$-fold change $\geq$ 0.5 and by an uncorrected p-value $\leq 0.05$. This intersection resulted in the detection of 156 genes that were differentially expressed in both conditions (Supp. Table S5 "Common gene-level analysis", and Figure 1D). These genes were used to query the Ingenuity IPA 7.0 knowledge database. The analysis identified Nervous System Development and Function as the top affected biological function (Table 4). Moreover, 28 genes were found to be associated to neurological disorders, 8 to axonal guidance signalling, 2 to glycosphingolipid biosynthesis, and 3 to the glycerolipid metabolism (Supp. Table S6). Additional genes involved in neuritogenesis were differentially expressed in only one of the two data sets (Supp. Table S6).

\section{Exon-level profiling reveals the expression of alternative mRNA isoforms}

Array data were next examined for evidence of differential exon expression, i. e. alternative pre-mRNA splicing. To remove low intensity signals only genes characterized by $\log _{2} \geq 5$ were considered. Moreover, analysis was restricted to 4148 transcripts characterized by having at least two mRNA isoforms annotated in the Ensembl database. Exon probesets intensity signals were normalized with respect to gene-level signals to generate "splicing index" values (see Materials and Methods). 
Differentially expressed exon probe sets, i.e. putative alternative splicing events (ASEs), were detected according to Della Beffa et al. (Della Beffa, et al., 2008). The integration of the results of MiDAS (Gardina, et al., 2006) and Rank Product (Breitling, et al., 2004) characterized by a $\mathrm{p} \leq 0.05$ lead to the identification of 816 putative ASEs, associated to 521 genes (Supp. Table S3 "PQ-ASEs"). Analysis with IPA 7.0 identified Cellular Growth and Proliferation, Cell Death, and Cell Cycle as the most affected cellular and molecular functions (Table 5).

A similar analysis was performed for the G93A-SOD1 experiment. A total of 406 putative ASEs, associated to 242 genes were eventually identified (Supporting Material, Table S4 "SOD1 ASEs"). In this case, pathway analysis detected Calcium Signaling, cAMP-mediated Signaling, and G-Protein Coupled Receptor Signaling as the most affected top canonical pathways (Table 6). Therefore from the in silico analysis of the alternative splicing data, the two experimental paradigms appear to differentially affect pre-mRNA splicing. Indeed, the integration of the two exon-level datasets led to the identification of only 48 common ASEs associated to 40 genes (Supp. Table S7, "Common ASEs"). Interestingly, 10 of these common genes function in Cellular Movement. Finally, we examined the position of the alternatively spliced exons with respect to their position in RefSeq transcripts. We classified exons as initial, internal or last. According to this classification 14 events affected initial exons, 3 occurred in terminal exons, and 24 fell in internal exons. Seven events could either not be assigned or occurred in intronic positions. Interestingly, 9 events $(18,7 \%)$ reflected the possible use of alternative promoters. This observation is consistent with the result of the analyses of the ENCODE regions (Birney, et al., 2007), which identified $>20 \%$ of genes having functional alternative promoters (Cooper, et al., 2006). Finally, 18 out of 40 common AS genes are also differentially 
expressed. However, of these only 50\% undergo putive ASEs affecting internal exons. This result is consistent with previous reports that suggest that regulation of AS of cassette exons and regulation of transcription appear to act on separate genes (Pan, et al., 2004).

Experimental validation of the gene-level analysis of the microarray data confirmed altered expression of axon guidance genes

We first performed the experimental validation of the gene expression data obtained from the PQ experiment. Different cellular and biochemical approaches confirmed the soundness of the microarray data and the biological significance of the pathways identified with IPA 7.0 (see Supporting Material "Results" and Supp. Figure S1). For the validation of the gene-level data obtained from the intersection of the two experimental paradigms we chose twelve of the 156 differentially expressed genes that showed a common trend upon PQ treatment and in G93A-SOD1 cells. Genes were prioritized by fold change variation and functional classification. Specifically, we focused on genes encoding molecules involved in the Nervous System Development and Function category. Expression of these genes was analyzed by quantitative real-time reverse-transcriptase polymerase chain reaction (RT-qPCR). As shown in Figure 2, qRT-PCR data were in good agreement to the microarray results for all genes except for VSNL1 and ADAMTS1.

As mentioned above, pathway analysis of the genes that showed a common trend in the two experimental paradigms identified eight genes involved in axon guidance signalling (Supp. Table S6). Additional axon guidance genes were differentially expressed in only one of the two dataset. More genes related to different aspects of neuritogenesis (transcription regulation of axon guidance molecules, intracellular 
1

2

3

4

5

6

7

8

9

10

signalling, etc.) were also found differentially expressed in both data sets. To identify molecular interactions among these genes we analyzed them further by IPA 7.0. The Ingenuity program can convert data sets into networks containing direct and indirect relationships between genes based on known interactions in the literature. The software is capable not only of constructing associations of genes identified by microarray (including relative expression levels), but also of predicting involvement of additional molecules not associated with significant transcriptional changes. We thus compiled a list of genes related to neuritogenesis from which the Ingenuity software created a network, on which our transcriptomics data were overlaid. In this network the 24 genes that were differentially expressed in our data sets were connected to 16 additional genes (Figure 3A). The network contained several transcription factors that are interconnected and involved in neuronal commitment and differentiation (ASCL1, ERBB3/4, NEUROG3, NKX2.2, and PAXO). Of these genes, NKX2.2, and PAX6 have been shown to play crucial roles in controlling the timing of neuritogenesis and gliogenesis in the developing ventral spinal cord modulating the activities of the proneural factors NEUROG1/2/3, and ASCL1 (Sugimori, et al., 2007). Interestingly, ASCL1 is strongly downregulated both in PQ-treated and in G93ASOD1 cells. In addition, the network connected genes encoding cytoplasmic proteins that may regulate actin dynamics such as WASF3 and $E V L$.

Hierarchical cluster analyses of the expression data of the subset of genes involved in neuritogenesis identified the majority of them as being downregulated (Figure 3B). qPCR analysis of a subset of these genes confirmed the array data (Figure 3C). We also tested by Western blotting the level of SEMA3A in the supernatant of PQ-treated and G93A-SOD1 cells as well as the expression of NTRK1. As shown in Figure 3D and $3 \mathrm{E}$, these experiments confirmed the increased expression of the repulsive 
SEMA3A and the downregulation of the neurotrophin receptor NTRK1 in both our models of mitochondrial dysfunction. Taken together these results suggest the formation of an altered, possibly more chemorepulsive cell environment.

\section{Altered expression of genes involved in neuritogenesis in G93A-Sod1 mice}

To determine whether changes in the expression of genes involved in axon growth and guidance could be observed in an animal model of neurodegeneration, we investigated the expression of a subset of the identified genes in the G93A-Sod1 mouse model of ALS. Disease onset in our strain is around 120 days (Pizzasegola, et al., 2009). Thirteen of the differentially expressed genes involved in neuritogenesis were analyzed by RT-qPCR on RNA extracted from spinal cord and brain of four transgenic mice carrying the G93A-Sodl mutation and three normal control littermates at 150 d. As shown in Figure 4A, this study confirmed the differential expression of Hgf, Cxcr4, and Sema3A in the spinal cord of symptomatic G93A-Sod1 mice. Thus, we decided to further characterize the alteration in the expression of eleven genes in the spinal cord of G93A-Sod1 mice during disease progression. We analyzed by RT-qPCR the expression profile of some of the genes identified in the microarray analysis (Cxcr4, Hgf, Ntrk1, Prphl, Sema3A, and Wasf3) and also of additional genes inferred from the literature (Nrp2, and Sept2) at the pre-onset (93, 103, and 113 days), onset (135 days), and symptomatic stage (140 - 170 days). Expression of Cxcr4 and Hgf increased significantly over time during disease course ( $\mathrm{p}=0.01$ for Cxcr4., and $\mathrm{p}<0.001$ for Hgf, Figure 4B), while Wasf3 and Sept2 showed increased expression in spinal cord of G93A-Sodl mice at early symptomatic stage (Figure 4C). 
Experimental validation of alternative splicing events

Next, we went on to confirm the putative ASEs identified by the exon-level analysis. We chose ASEs affecting 15 transcripts involved in the top canonical pathways identified with IPA 7.0. In particular, we focused on genes involved in Nervous System Development and Function, which appeared to be affected by AS changes in either one, or both experimental paradigms. The location of the differentially expressed exon-probe set was manually inspected with the X:map software (Okoniewski, et al., 2007; Yates, et al., 2008) to determine its position on the transcripts annotated in Ensembl. Only ASEs occurring in exons for which there is at least one annotated alternative isoform were subjected to experimental validation by RT-PCR. All the amplified fragments were subcloned and sequenced to verify the identity of the splicing isoforms.

The Human Exon 1.0 ST array can identify mRNA variants that differ in the use of exons, introns, promoters and polyadenylation sites. In the case of the RPRDIA gene the microarray data predicted an increased inclusion of exon 8 (identified by the probe set n. 3874170, boxed in Figure 5A). In the Ensembl database there are four transcripts annotated for this gene, one of which contains exon 8. To validate this ASE, RT-PCR analysis was performed with two forward primers (in exons 8 and 9) and a single reverse primer in exon 5 (Figure 5B). As shown in Figure 5C, RT-PCR confirmed the expected inclusion of exon 8 in G93A-SOD1 cells.

Two potential ASE were also predicted to occur in the BIN1 gene. Specifically, microarray data predicted inclusion of exon 7 and skipping of exon 15 in PQ-treated cells. In G93A-SOD1 cells the array data predicted inclusion of exon 15. To validate these ASEs, we amplified by PCR the relevant region of each mRNA using primers in 
constitutive flanking exons (Figure 5, panels D to F). Sequencing of the PCR fragments confirmed the inclusion of exon 7. Unfortunately, we could not detect the event affecting exon 15. Instead, we observed a splicing switch affecting exons 14 and 16, which was not predicted by the array. The presence of some discrepancies between microarray data and RT-PCR is due to the limited statistical power of an exon-level analysis. We tried to address this issue by using 5 biological replicates for each microarray experiment and by reducing the number of tested hypotheses, focusing the analysis only on expressed exons associated to annotated mRNA isoforms. Nevertheless, the multiple testing problem remains a critical issue in the exon-level analysis of array data (Della Beffa, et al., 2008). Additional ASEs in internal exons were confirmed for GNAOI (Figure 4G) and for NRG1 (data not shown).

Among the probe sets exhibiting changes in expression, several mapped to the 5' end of the transcripts and were considered to be candidate alternative first exons. We considered the case of the ABLIM1 gene for which several different alternatively spliced transcripts have been identified, some of them most likely transcribed from alternative promoters (Figure 6A). The probe set intensities along the entire ABLIMI gene are shown in Figure 6B. The exon array data predicted the skipping of an internal first exon in both experimental paradigms exon (boxed in Fig. 6B, see also the schematic representations in panels $6 \mathrm{~A}$ and $6 \mathrm{C}$ ). To validate this event we performed a semiquantitative PCR with two forward primers and a single reverse primer. This type of competitive PCR reactions have been used previously to detect variations in expression of 5'- and 3'-terminal exons (Karni, et al., 2007; Yamamoto, et al., 2009). As shown in Figure 6C, both upon PQ treatment and in G93A-SOD1 cells the amount of the PCR fragment corresponding to the mRNA transcribed from 
1

2

3

4

5

6

7

8

9

10

the distal promoter increased relative to the shorter fragment corresponding to the mRNA transcribed from the alternative, internal promoter, thus confirming the microarray prediction.

Three additional examples of alternative first exon usage that were similarly predicted by the exon array data were verified by RT-PCR $(C H N 1, L M O 3$, and $N R G 1$, Figure 6D). In the case of the $C H N 1$ gene, the skipping of an alternative first exon upon PQ treatment and its inclusion in G93A-SOD1 cells was confirmed by qPCR (Figure 6E) The switches in first exon usage for ABLIM1, CHNI, and NRG1 strongly influence the coding potential of the different mRNA isoforms (Figure 6F). In the case of the ABLIM1 gene, we observed an increase of the longer transcript variant, which encodes a protein that contains four LIM domains. These domains are not present in the isoform encoded by the mRNA variant transcribed from the internal first exon. Similarly, the short CHN1 isoform that is differentially expressed upon PQ treatment and in SOD1(G93A) cells lacks an SH2 domain. In contrast, the switch of first exons in the $\mathrm{LMO}$ gene results in different $5^{\prime}$ ' UTR sequences for the different transcripts.

\section{Discussion}

In this study we sought to contribute to the understanding of the link between mitochondrial stress and neurodegeneration. To this end we performed a wholegenome analysis using splicing-sensitive microarrays of two different cellular paradigms of mitochondrial dysfunction. First, we profiled human SH-SY5Y neuroblastoma cells untreated or treated with $\mathrm{PQ}$, a redox cycling molecule that induces mitochondrial damage. Second, we compared SH-SY5Y cells stably expressing wild type SOD1 to cells expressing the mutant G93A-SOD1 protein. Mutations in SOD1 are one of the genetic causes of ALS. The mutant proteins have 
been found in mitochondria and are believed to cause multiple damages (for review see (Shi, et al.). The data sets from the two experimental paradigms were then integrated in order to identify common deregulated genes.

Our findings indicate that mitochondrial damage can induce profound changes in the expression of genes involved in relevant pathways for neuronal survival, both at the gene-level and in pre-mRNA splicing. In addition to previously described changes in the expression of cytoskeletal and molecular motor proteins ("Cell Movement"), we identified alterations of a subset of genes involved in Nervous System Development and Function, including axon growth and guidance genes, and genes encoding proteins involved in synaptic vesicles formation. Changes in the expression of a subset of the identified genes were confirmed in the G93A-Sod1 mouse, a model for ALS, supporting the idea that alterations in the expression of this category of genes may contribute to explain the vulnerability of synapses and distal axons observed in many neurodegenerative diseases (for review see (Conforti, et al., 2007).

\section{Cell Movement}

Recent studies have shown that neurons in general, and even more so motor neurons, are highly sensitive to defects in axonal transport due to their extreme polarization. Decreased kinesin-mediated (anterograde) and dynein-mediated (retrograde) axonal transport have been observed both in ALS patients and in transgenic animal models (for review see (De Vos, et al., 2008; Strom, et al., 2008)). In G93A-Sod1 transgenic mice, a considerable inhibition of retrograde axonal transport was observed at a very early stage of disease before animals became symptomatic (Jiang, et al., 2005). We observed downregulation of several members of the kinesin family in both experimental paradigms. In the G93A-SOD1 experiment is particularly noteworthy 
1

2

3

4

5

6

7

8

9

10

the downregulation of KIF1A, an anterograde motor protein. Altered expression of KIF1A had already been reported in 75-days old G86R-Sod1 mice (Dupuis, et al., 2000). The phenotype of KiflA knockout mice includes motor and sensory disturbances, a reduction in the density of synaptic vesicles in nerve terminals, and accumulation of clear vesicles in nerve cell bodies (Yonekawa, et al., 1998). KIF1A cargos include a subset of precursors for synaptic vesicles: synaptophysin, synaptotagmin, and Rab3A. In this context it should be mentioned that we also observed altered expression of several genes involved in synaptic function including three members of the synaptotagmin family (SYT2, SYT4, and SYT12, which encode integral membrane proteins of synaptic vesicles), synaptojanin-2 (SYNJ2, coding for a phosphoinositide phosphatase implicated in cytoskeletal dynamics during endocytosis) as well as genes encoding components of the presynaptic active zone (RIM1, and RIM3). Consistent with these data, pre-degenerative depletion of synaptic vesicles has been reported in ALS (Pun, et al., 2006).

In G93A-SOD1 cells, we also observed downregulation myosin X (MYO10) coding for another molecular motor, while PQ treatment induced upregulation of MYLIP (myosin regulatory light chain interacting protein). MYLIP is expressed in the cell bodies and growth cones of rat embryonic hippocampal neurons, and belongs to a family of cytoskeletal effector proteins that link actin to membrane-bound proteins at the cell surface. Interestingly, in rat PC12 neural precursor cells, MYLIP overexpression inhibited NGF-induced neurite outgrowth (Olsson, et al., 2000; Olsson, et al., 1999). Overall, these data reinforce the concept that alteration of axonal transport is involved in neurodegeneration, and suggest that this alteration may descend directly from mitochondrial damage. 
Nervous System Development and Function

As mentioned above, pathway analysis of the genes that were differentially expressed in both experimental paradigms highlighted several genes associated to axon guidance (Supp. Table S6). Axon guidance is a partially understood process that has a major role not only in embryonic development (O'Donnell, et al., 2009) but in the maintenance of the mature peripheral nervous system as well (Yoo, et al., 2009). Several lines of evidence support the hypothesis that aberrant expression of axon guidance proteins such as Semaphorins, Ephrins, Netrins and Slits, may induce pathological changes in motor neurons and contribute to the pathogenesis of ALS ((Schmidt, et al., 2009). Both in PQ-treated cells as well as in G93A-SOD1cells we observed downregulation of SEMA6A and of its receptor PLXNA4. Moreover, SEMA3D is among the top upregulated genes in both datasets. This semaphorin is expressed at the dorsal spinal cord midline and appears to guide axons by repulsion and modulation of fasciculation (Wolman, et al., 2004).

Additional genes coding for axon guidance molecules were differentially expressed in either one of the two experimental paradigms. For example, in G93A-SOD1 cells we observed upregulation of neuropilin 2 (NRP2), coding for a selective receptor for class 3 semaphorins that is required for the development of central nervous system and peripheral nervous system projections (Giger, et al., 2000), and of SEMA3A, a chemorepellant for cortical axons and an inhibitor of axonal regeneration and other regenerative responses after spinal cord injury (Kaneko, et al., 2006).

Paraquat treatment induced downregulation of $S E M A 3 F$, and $S E M A 6 D$. Interestingly, an association between SEMA6A polymorphisms and ALS has previously been reported (Lesnick, et al., 2008). Also noteworthy is the reduction in NTRK1 expression, a neurotrophin receptor that is thought to play a role in axon guidance and 
outgrowth in conjunction with SEMA3A. In addition, we observed reduced expression of $S D C 2$, coding for a member of the heparan sulphate proteoglycan (HSPG) family of extracellular matrix proteins both in PQ-treated and in G93A-SOD1 cells. Some axon guidance molecules bind to HSPGs, and this modulates their repulsive properties (Jokic, et al., 2006). Thus, the downregulation of SDC2 might suggest a shift to a more repulsive character of the extracellular matrix. This effect is possibly aggravated by the upregulation of SEMA3D and the downregulation of SEMA6A.

In both experimental paradigms we observed altered expression not only of classical members of the ligand/receptor axon guidance systems but also of genes involved in a broader sense in neuritogenesis, such as genes encoding downstream intracellular signal transduction molecules and upstream transcription factors that control axonal patterning (for review see O'Donnell, et al., 2009; Polleux, et al., 2007). For example, in G93A-SOD1 cells we observed upregulation of RGNEF (Rho-guanine nucleotide exchange factor). RGNEF is a human homologue of mouse p190RhoGEF, a low molecular weight neurofilament (NFL) mRNA stability factor that was shown to be involved in NF aggregate formation in neurons (Lin, et al., 2005; Volkening, et al., 2009). In PQ-treated cells we found the downregulation of three genes (ISL1, LHX8, and $L H X 9$ ) that belong to the family of LIM homeobox transcription factors. It has been shown that in the developing mouse spinal cord Isl1 and Lhx1 control the dorsoventral specificity of motor axon projections at least in part by controlling the expression of EphA4 (Kania, et al., 2000). Interestingly, LHX9 is also downregulated in G93A-SOD1 cells.

A validation of the microarray data in G93A-Sodl mice confirmed the alterations in the expression of neuritogenesis genes during disease progression. For example, we 
observed a progressive increase in the expression of $\mathrm{Hg}$ during disease course. HGF, which has neurotrophic effects in the motor neurons and central nervous system, was found to be upregulated in motor neurons of sporadic ALS patients (Jiang, et al., 2005). In addition we found increased expression of $C x c r 4$ from pre-symptomatic to end-stage. CXCR4 and its ligand SDF1 regulate neural development by modulating cell migration and axon growth and guidance and by promoting cell survival and proliferation (Chalasani, et al., 2003; Stumm and Hollt, 2007; Zou, et al., 1998) .

Taken together, our data indicate that mitochondrial stress can induce transcriptional alterations of multiple genes involved in neuritogenesis, and are in agreement with the observation that dorsal root ganglia neurons from adult mice expressing G93A-Sod1 in culture grow shorter neurites (Perlson, et al., 2009). The idea that differential expression of genes relating to the growth of neuronal processes, and formation of synapses may play a role in neurodegeneration is supported by a recent micrroarray analysis of spinal motor neurons of Vegf/o mice, a different ALS mouse model (Brockington, et al.). Since it has been observed that in neuromuscular diseases such as ALS selective synaptic weakening and denervation start long before the actual motor neuron loss, and prior to the appearance of clinical symptoms (Fischer, et al., 2004), the expression of repulsive signals could act during the presymptomatic stages and contribute to the retraction of axon terminals from the neuromuscular synapse before the death of motor neurons occurs.

\section{Changes in alternative pre-mRNA splicing}

RNA-based mechanisms have been implicated in several neurodegenerative conditions leading to the recognition of new pathogenic pathways (for review see (Licatalosi and Darnell, 2006; Strong, 2009). In ALS, numerous reports have 
1

2

3

4

5

6

7

8

9

10

highlighted differential expression of protein isoforms, which arise from AS events in the affected tissues of patients, as well as in the mouse models (Aerbajinai, et al., 2002; Munch, et al., 2002; Pantelidou, et al., 2007; Robertson, et al., 2003; Tomiyama, et al., 2002). RNA processing has been further implicated in ALS pathogenesis by the recent characterization of mutations in two DNA/RNA-binding proteins (TDP43 and FUS/TLS) in familial and sporadic patients (for review see (Lagier-Tourenne and Cleveland, 2009; Strong, 2009).

Exon-level analysis of our microarray data detected a widespread alteration in premRNA splicing. We selected for experimental validation events affecting genes involved in the pathways mentioned above (i.e. Cell Movement and Nervous System Development and Function). For example, the ABLIM1 gene encodes a cytoskeletal protein that binds to actin filaments. The C. elegans homolog UNC-115 was shown to act as a downstream cytoskeletal effector of Rac signaling in axon pathfinding (Gitai, et al., 2003; Struckhoff and Lundquist, 2003). Our data indicate that alternative promoter usage modulates the ration between mRNAs encoding the full-length protein or a shorter isoform lacking the LIM zinc-finger domain, which is thought to mediate protein:protein interactions. A second example is provided by CHN1. This gene codes for two different isoforms of a signaling protein implicated in the pathfinding of corticospinal axons in mice brain (Brown, et al., 2004). Upon PQ treatment we observed a decrease of the mRNA encoding the short isoform, and therefore a relative increase in the expression of the long isoform. The two protein isoforms share a RacGAP domain that interacts with and down-regulates Rac activity. However, the long isoform (alpha2-chimerin) contains an N-terminal $\mathrm{SH} 2$ domain that is not present in the short isoform, transcribed from an internal promoter. Shi et al. showed that the longer isoform is required for EphA4 -dependent growth cone 
collapse (Shi, et al., 2007). Finally, we observed changes in the alternative splicing pattern of BIN1. This was especially intriguing given the known interactions of BIN1 with dynamin in pre-synaptic membranes of the nervous system and its role in endocytic recycling (Leprince, et al., 2003; Nicot, et al., 2007; Pant, et al., 2009; Takei, et al., 1999). These findings suggest that mitochondrial dysfunction may have a severe effect not only on transcription but also on pre-mRNA splicing of a subset of genes that participate in biological processes that are relevant for neurodegeneration.

But how do these splicing changes arise? Expression of neuron-specific proteins involved in RNA splicing and metabolism is affected in several neurological disorders (Licatalosi and Darnell, 2006). Surprisingly, in our experiments we did not detect any differentially expressed gene encoding a splicing regulatory factor. The only gene coding for an RNA-binding protein, which is differentially expressed in both paradigms, is ELAVL2 (Supp. Table S5),one of the mammalian homologs of ELAV, a protein essential for neurogenesis in Drosophila (Robinow et al., 1988). ELAVL2 encodes the neuronal $\mathrm{HuB}$ protein that binds and stabilizes $\mathrm{t}$ a $\mathrm{r}$ g e $\mathrm{t}$ $\mathrm{m} \mathrm{R}$ As containing A $\mathrm{U}$ - rich e 1 e $\mathrm{m} \mathrm{e} \mathrm{n} t \mathrm{~s}$

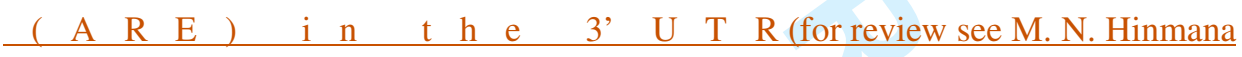
and H. Lou, 2008). Instead, among the common ASEs (Supp. Table S7) we found $C U G B P 2$, a well-known alternative splicing factor (for review see Barreau, et al., 2006). CUG-BP2 is particularly relevant in the context of neurodegeneration since it $\underline{\text { has a specific neuromuscular expression and is differentially expressed in several }}$ models of SMA (Anderson, et al., 2004). The putative ASE affecting the CUGBP2 $\underline{\text { transcript occurs in the 3' UTR and may thus influence either intracellular localization }}$ or stability of the mRNA. This in turn may affect splicing, stability and/or translation of specific transcripts. 
If mitochondria stress does not lead to extensive changes in the expression of splicing regulatory proteins AS alterations may be the consequence of post-translational modifications of splicing regulatory proteins that change their activity and/or intracellular distribution. Indeed, it has already been documented that different types of cell stress (osmotic stress, heat-shock, or arsenite treatment) result in altered phosphorylation and intracellular localization of members of the hnRNP and SR families of splicing factors (for review see Biamonti and Caceres, 2009). It is clear that alterations in the expression and activity induced by cellular stress are mediated through the interplay of multiple signalling pathways. Which mechanisms of signal transduction respond to mitochondrial stress thereby causing derangement of splicing needs further elucidation.

In conclusion, whole genome exon level profiling of our cellular models has identified neuritogenesis and axon guidance as relevant pathways specifically altered by mitochondrial dysfunction. Dysregulation occurs at the level of both gene expression and alternative pre-mRNA splicing. Genes controlling axon outgrowth and guidance, and synapse formation play a fundamental role during embryonic development in the establishment of functional circuits. However, they also function in the mature mammalian CNS where many neurons retain a limited degree of structural plasticity. Changes in neural connectivity and loss of synaptic contacts are a unifying hallmark of neurodegenerative disorders. Further studies are needed to determine whether a reduction of neurotrophic factors and the establishment of a repulsive environment may contribute to axonal degeneration and cell death in these disorders.

Deleted: Therefore, we can hypothesize
that the
$\begin{aligned} & \text { Deleted: in pre-mRNA splicing } \\ & \text { observed in our experimental paradigms } \\ & \text { of mitochondrial stress }\end{aligned}$
Deleted: arise
Deleted: by
Deleted: thereby
Deleted: changing




\section{Acknowledgements}

This work was supported by grants from Fondazione Cariplo to T.A., S.B., and M.T.C., from MIUR-PRIN to S.B. and M.T.C., from EC 7FPs TOLERAGE 202156 and FIGHT 242210 to F. Zolezzi and D.B., and from Regione Piemonte to R.C.; F. Cordero is supported by a grant from Regione Piemonte/Università di Torino. We thank R. Ambrosini for help with the statistical analysis of the in vivo data, and D. Talarico for carefully reading the manuscript and for helpful suggestions.

\section{Supporting Material}

File 1. Assessment of RNA quality

File 2. Supporting Results and Methods

File 3. Assessment of RNA and arrays quality .

Table S1. "Paraquat gene-level analysis"

Table S2. "SOD1 gene-level analysis"

Table S3. "PQ exon-level analysis"

Table S4. "SOD1 exon-level analysis"

Table S5. "Common gene-level"

Table S6. Genes associated to Neurological Disorder, Axonal Guidance Signaling, and Neuritogenesis.

Table S7. "Common ASEs"

Table S8. Main Entrez Gene abbreviations used in the text

Table S9. Oligonucleotide primers 
1

2

3

4

5

6

7

8

9

\section{Figure Legends}

Figure 1. Whole genome, splicing-sensitive microarray analysis of the cellular response to mitochondrial dysfunction.

A. Diagram of the experimental design.

B. Gene-level hierarchical cluster analysis of untreated vs. PQ-samples and WTSOD1 vs. G93A-SOD1 samples. The two dendrograms (sample level hierarchical clustering with average linkage) represent the relative distance between samples.

C. Exon-level hierarchical cluster analysis of untreated vs. PQ-samples and WTSOD1 vs. G93A-SOD1 samples.

D. Venn diagram illustrating the overlap between differentially expressed genes in the PQ-experiment and in the G93A-SOD1 experiment.

Figure 2. Experimental validation of the gene-level microarray data in SH-SY5Y cells.

qPCR validation of array data from the PQ and G93A-SOD1 experiments. Assays were performed in triplicate from a pool of the RNA samples used for the microarray analysis and from two different RNA preparations.

Figure 3. Mitochondrial dysfunction alters expression and splicing of genes involved in axon growth and guidance.

A. A gene-interaction network of genes related to axon growth and guidance. Transcriptomics data were overlaid on a genetic network generated with the Ingenuity Pathway Analysis 7.0 software. This diagram is a graphical representation of 24 genes (in green), whose expression is altered in our 
experimental paradigms of mitochondrial dysfunction, and of 16 additional genes (in grey) that may be involved in various aspects of neuritogenesis. Gene products are represented as nodes, and the biological relationship between two nodes is represented as an edge (line). All edges are supported by at least one reference from the literature, a textbook, or canonical Material stored in the Ingenuity Pathways Knowledge Base. Solid lines between genes represent known direct molecular interactions, and dashed lines, known indirect molecular interactions. Nodes are displayed by using various shapes that represent the functional class of the gene product.

B. Hierarchical cluster analysis of genes involved in axon growth and guidance whose expression is altered in the two experimental paradigms. The dendrograms represent the relative distance between samples (top) and between genes (left). Expression signal intensities are shown in red and green, indicating high and low expression, respectively. The Entrez GeneID is indicated on the right of each panel.

C. qPCR validation of the expression of the microarray data for genes involved in axon growth and guidance in SH-SY5Y cells. Experiments were performed in triplicates on three biological replicates. The Y-axis is expressed as means \pm standard error (SE). Samples identified by two asterisks are considered very significant ( $\mathrm{p}$ value $=0.001$ to 0.01 ) while those labelled with one asterisk are considered significant ( $\mathrm{p}$ value $=0.01$ to 0.05 )

D. Western blot analysis of NTRK1 expression in untreated and PQ-treated SHSY5Y cells (left panel) and in SH-SY5Y cells expressing wild type SOD1 or G93A-SOD1 (right panel). Expression of beta-actin was used as an internal control. Data are representative of three independent experiments. 
1

2

3

4

5

6

7

8

9

10

11

12

13

14

E. Determination of SEMA3A expression in culture supernatants of untreated and PQ-treated SH-SY5Y cells (left panel) and of SH-SY5Y cells expressing wild type SOD1 or G93A-SOD1 (right panel). Cells were cultured in normal growth medium for 24 hours, and then shifted to serum-free medium for $18 \mathrm{~h}$. Supernatants were concentrated as described in Materials and Methods. Western blot analysis was done one equal volume of concentrated supernatant. To normalize the amounts of secreted protein to the cell number, cells were lysed in equivalent volumes of buffer. Western blot analysis of b-actin was done on the same volume of cell extract from each sample. Data are representative of three independent experiments.

Figure 4. Analysis of the expression of genes involved in neuritogenesis in the G93A-Sod1 mouse model.

A. qPCR analysis of the expression of a subset of axon guidance genes in spinal cord and brain of symptomatic G93A-Sod1 mice. Total RNA was extracted from spinal chord and brain of mice at 150 days of age. Data are presented means \pm standard error of the mean of three technical replicates of age-matched non-transgenic controls $(n=3)$ and disease $(n=4)$ spinal cord and brain samples. By a 2-tailed t-test $H g f$ is considered extremely significant ( $\mathrm{p} \leq 0,0001$ ), Cxcr 4 very significant $(p=0.0042)$, and Sema3A significant $(p=0.0167)$.

B. Time course of $H g f$ and $C x c r 4$ mRNA expression in the spinal cord of G93ASodl mice during disease progression. Total RNA was isolated from the spinal cord of G93A-SOD1(closed circles) or age-matched non-transgenic control animals (opened circles) on different days from the pre-onset till the symptomatic stage (93-170 days). Expression was analyzed by RT-qPCR and 
normalized to Hprt1 mRNA. Standard curves represent the correlation between delta $\mathrm{Ct}($ transcript $)$ and age. A decrease in $\mathrm{Ct}$ value correlates with an increase of transcript level. Data were analyzed with a linear regression model. The difference in slope between the two straight lines is very significant for Cxcr4 $(\mathrm{r}-\mathrm{squared}=0.911, \mathrm{t}=7.905, \mathrm{p}=0.01)$ and extremely significant for Hgf $(\mathrm{r}-$ squared $=0.635, \mathrm{t}=2.823$, a $\mathrm{p}<0.001)$.

C. Wasf3 and Sept 2 mRNA expression is upregulated in the spinal cord of G93ASOD1 mice at the early symptomatic stage. Spinal cord samples were grouped in pre-onset phase $(93,103$, and 113 days; Ntg: $n=6$; G93A: $n=5)$, early symptomatic phase (135 days; Ntg: $\mathrm{n}=2$; G93A: $\mathrm{n}=2$ ) and symptomatic phase (145, 155, 170 days; Ntg: $n=3$; G93A: $n=7)$. Each sample was analysed in duplicates. Each bar represents the mean $\pm \mathrm{s}$ tandard error of each group normalized to the mean value of the control samples at pre-onset.

Figure 5. Experimental validation of the alternative internal exons identified by microarray analysis.

A. Identification of differential alternative splicing by exon array probeset-level expression data for the entire RPRDIA gene in the PQ experiment. Plotted are expression levels (y-axis) for each probeset (x-axis). Non-parallel probe set expression levels, highlighted by a box, indicate region-dependent differential splicing of the corresponding exon. Black line untreated; grey line: PQ-treated.

B. Exon structure of the human RPRDIA transcripts annotated in the Ensembl database. Indicated are the alternative exon 8 (e8), the position of the PCR primers, and the size of the expected products ( $359 \mathrm{bp}$ and $968 \mathrm{bp}$ ).

C. RT-PCR validation of the exon array prediction for the inclusion of exon 8 in 
1

2

3

4

5

6

7

8

9

10

11

12

13

14

15

16

17

18

19

20

21

22

23

24

25

26

27

28

29

30

31

32

33

34

35

36

37

38

39

40

41

42

43

44

45

46

47

48

49

50

51

52

53

54

55

56

57

58

59

60

RPRD1A transcripts. The indicated fragments were subcloned and sequenced to verify their identity.

D. RT-PCR validation of the predicted ASEs for the BIN1 transcripts. The indicated splice forms were subcloned and sequenced to verify their identity. Left: analysis of PCR products validating alternative splicing changes. These products correspond to either the inclusion or the skipping of both e14 (ENSE00000925812) and e16 (ENSE00000964173), and the inclusion of e7 (ENSE00000925822). The asterisks indicate PCR products that do not change upon treatment. Right: diagrams of the relevant pre-mRNA region. Indicated are the positions of the PCR primers (arrow heads), the splicing pattern, and the size of the expected products (468 bp and $359 \mathrm{bp}$ ).

E. The bar graph represents the quantitation of the RNA splicing analysis for the exon 7 (e7) of the BINl gene. The inclusion of exon 7 after PQ treatment and in G93A-SOD1 cells was normalized relative to that observed in the respective controls (light grey bars). The dark grey bars show the average fold-increase of the isoform containing exon 7; error bars indicate the standard error. The asterisk represents the result of two-tailed t-test $(\mathrm{p}<0.05)$.

F. Quantitation of the alternative splicing of exon 14 (e14) and exon 16 (e16) of the BINl gene. The dark grey bars show the average fold-increase after PQ treatment normalized to the untreated control (light grey bars). Error bars indicate the standard error. The asterisks represent the result of two-tailed t-test $(\mathrm{p} \leq 0.001)$

G. Alternative splicing of GNAO1. The dark grey bars show the average fold increase of the isoform containing exon 10 (ENSE00001322402) after PQ treatment and in G93A-SOD1 cells. Error bars indicate the standard error. The 
asterisk represents the result of two-tailed t-test $(\mathrm{p} \leq 0.05)$.

Figure 6. Experimental validation of the alternative first exons identified by microarray analysis.

A. Exon structure of the human ABLIMI transcripts annotated in the NCBI database.

B. Identification of differential alternative splicing by exon array probe set-level expression data for the entire ABLIM1 gene in the paraquat (left panel) and the G93A-SOD1 (right panel) experiments. Plotted are the average signal intensities (y-axis) for each probe set (x-axis). The box indicates the internal first exon (exon-level probe set id: 3308001, Ensembl id: ENSE00001449337, ENSE00001513698, ENSE00001449334) validated by competitive RT-PCR. Black line untreated or WT-SOD1; red line: PQ-treated or G93A-SOD1.

C. RT-PCR validation of the exon array prediction for the ABLIM1 transcript. The indicated splice forms were subcloned and sequenced to verify their identity. Left: analysis of PCR products validating alternative splicing changes. Right: diagrams of the relevant pre-mRNA region. Indicated are: the position of the PCR primers (arrow heads), the splicing pattern, and the size of the expected products.

D. RT-PCR validation of the exon array prediction for three additional genes. Common names of the alternatively spliced transcripts are as follows: CHNI, chimerin 1 (GTPase-activating protein for p21-rac and a phorbol ester receptor); LMO3, LIM domain only 3 (neuronal basic helix-loop-helix protein); $N R G 1$, neuregulin 1 (a signaling protein). The indicated fragments were subcloned and sequenced to verify their identity. Left: analysis of PCR 
1

2

3

4

5

6

7

8

9

10

11

12

13

14

15

16

17

18

19

20

21

22

23

24

25

26

27

28

29

30

31

32

33

34

35

36

37

38

39

40

41

42

43

44

45

46

47

48

49

50

51

52

53

54

55

products validating alternative splicing changes. Right: diagrams of the relevant pre-mRNA region. Indicated are the positions of the PCR primers (arrow heads), the splicing pattern, and the size of the expected products.

E. Confirmation of the region-specific alternative splicing pattern of CHN1 by qRT-PCR. The bar graph shows the ration of the expression level of the variant isoform in treated vs. untreated and WT-SOD1 vs. G93A-SOD1 cells. The mRNA variant containing the first alternative exon is reduced at least 2fold upon PQ treatment.

F. Graphical view of the PROSITE (Swiss Institute of Bioinformatics, (Gasteiger, et al., 2003) patterns predicted for the protein isoforms encoded by the alternative transcripts of the ABLIM1,CHN1, NRG1 genes. Domain legend: EGF_1, EGF-like domain signature 1; EGF_3, EGF-like domain profile; HP, Headpiece domain profile; IG_LIKE, Ig-like domain profile; LIM_DOMAIN_2, LIM domain profile; RHOGAP, Rho GTPase-activating proteins domain profile; $\mathrm{SH} 2$, Src homology 2 (SH2) domain profile; ZF_DAG_PE_2, Zinc finger phorbol-ester/DAG-type profile. 


\section{References}

Aerbajinai W, Ishihara T, Arahata K, Tsukahara T. 2002. Increased expression level of the splicing variant of SIP1 in motor neuron diseases. Int J Biochem Cell Biol 34(6):699-707.

Anderson KN, Baban D, Oliver PL, Potter A, Davies KE. 2004. Expression profiling in spinal muscular atrophy reveals an RNA binding protein deficit.

\section{Neuromuscul Disord 14(11):711-22.}

Barreau C, Paillard L, Mereau A, Osborne HB. 2006. Mammalian CELF/Bruno-like RNA-binding proteins: molecular characteristics and biological functions.

\section{Biochimie 88(5):515-25,}

Biamonti G, Caceres JF. 2009. Cellular stress and RNA splicing. Trends Biochem Sci 34(3):146-53.

Birney E, Stamatoyannopoulos JA, Dutta A, Guigo R, Gingeras TR, Margulies EH, Weng Z, Snyder M, Dermitzakis ET, Thurman RE and others. 2007. Identification and analysis of functional elements in $1 \%$ of the human genome by the ENCODE pilot project. Nature 447(7146):799-816.

Boillee S, Vande Velde C, Cleveland DW. 2006. ALS: a disease of motor neurons and their nonneuronal neighbors. Neuron 52(1):39-59.

Bolstad BM, Irizarry RA, Astrand M, Speed TP. 2003. A comparison of normalization methods for high density oligonucleotide array data based on variance and bias. Bioinformatics 19(2):185-93.

Breitling R, Armengaud P, Amtmann A, Herzyk P. 2004. Rank products: a simple, yet powerful, new method to detect differentially regulated genes in replicated microarray experiments. FEBS Lett 573(1-3):83-92. 
Brockington A, Heath PR, Holden H, Kasher P, Bender FL, Claes F, Lambrechts D, Sendtner M, Carmeliet P, Shaw PJ. 2010. Downregulation of genes with a function in axon outgrowth and synapse formation in motor neurones of the VEGF delta/delta mouse model of amyotrophic lateral sclerosis. BMC Genomics 11(1):203.

Brown M, Jacobs T, Eickholt B, Ferrari G, Teo M, Monfries C, Qi RZ, Leung T, Lim L, Hall C. 2004. Alpha2-chimaerin, cyclin-dependent Kinase 5/p35, and its target collapsin response mediator protein-2 are essential components in semaphorin 3A-induced growth-cone collapse. J Neurosci 24(41):8994-9004.

Carri MT, Ferri A, Battistoni A, Famhy L, Gabbianelli R, Poccia F, Rotilio G. 1997. Expression of a $\mathrm{Cu}, \mathrm{Zn}$ superoxide dismutase typical of familial amyotrophic lateral sclerosis induces mitochondrial alteration and increase of cytosolic $\mathrm{Ca} 2+$ concentration in transfected neuroblastoma SH-SY5Y cells. FEBS Lett 414(2):365-8.

Castello PR, Drechsel DA, Patel M. 2007. Mitochondria are a major source of paraquat-induced reactive oxygen species production in the brain. J Biol Chem 282(19):14186-93.

Chalasani SH, Sabelko KA, Sunshine MJ, Littman DR, Raper JA. 2003. A chemokine, SDF-1, reduces the effectiveness of multiple axonal repellents and is required for normal axon pathfinding. J Neurosci 23(4):1360-71.

Chio A, Schymick JC, Restagno G, Scholz SW, Lombardo F, Lai SL, Mora G, Fung HC, Britton A, Arepalli S and others. 2009. A two-stage genome-wide association study of sporadic amyotrophic lateral sclerosis. Hum Mol Genet 18(8):1524-32. 
Cicchetti F, Drouin-Ouellet J, Gross RE. 2009. Environmental toxins and Parkinson's

disease: what have we learned from pesticide-induced animal models? Trends

Pharmacol Sci 30(9):475-83.

Conforti L, Adalbert R, Coleman MP. 2007. Neuronal death: where does the end begin? Trends Neurosci 30(4):159-66.

Cooper SJ, Trinklein ND, Anton ED, Nguyen L, Myers RM. 2006. Comprehensive analysis of transcriptional promoter structure and function in $1 \%$ of the human genome. Genome Res 16(1):1-10.

Cooper TA, Wan L, Dreyfuss G. 2009. RNA and disease. Cell 136(4):777-93.

Cozzolino M, Ferri A, Carri MT. 2008. Amyotrophic lateral sclerosis: from current developments in the laboratory to clinical implications. Antioxid Redox Signal 10(3):405-43.

Cozzolino M, Pesaresi MG, Amori I, Crosio C, Ferri A, Nencini M, Carri MT. 2009. Oligomerization of mutant SOD1 in mitochondria of motoneuronal cells drives mitochondrial damage and cell toxicity. Antioxid Redox Signal 11(7):1547-58.

Damiano M, Starkov AA, Petri S, Kipiani K, Kiaei M, Mattiazzi M, Flint Beal M, Manfredi G. 2006. Neural mitochondrial Ca2+ capacity impairment precedes the onset of motor symptoms in $\mathrm{G} 93 \mathrm{~A} \mathrm{Cu} / \mathrm{Zn}$-superoxide dismutase mutant mice. J Neurochem 96(5):1349-61.

De Vos KJ, Grierson AJ, Ackerley S, Miller CC. 2008. Role of axonal transport in neurodegenerative diseases. Annu Rev Neurosci 31:151-73.

Della Beffa C, Cordero F, Calogero RA. 2008. Dissecting an alternative splicing analysis workflow for GeneChip Exon 1.0 ST Affymetrix arrays. BMC Genomics 9:571. 
Dupuis L, de Tapia M, Rene F, Lutz-Bucher B, Gordon JW, Mercken L, Pradier L, Loeffler JP. 2000. Differential screening of mutated SOD1 transgenic mice reveals early up-regulation of a fast axonal transport component in spinal cord motor neurons. Neurobiol Dis 7(4):274-85.

Edgar R, Domrachev M, Lash AE. 2002. Gene Expression Omnibus: NCBI gene expression and hybridization array data repository. Nucleic Acids Res 30(1):207-10 .

Ferri A, Cozzolino M, Crosio C, Nencini M, Casciati A, Gralla EB, Rotilio G, Valentine JS, Carri MT. 2006. Familial ALS-superoxide dismutases associate with mitochondria and shift their redox potentials. Proc Natl Acad Sci U S A 103(37):13860-5

Fischer LR, Culver DG, Tennant P, Davis AA, Wang M, Castellano-Sanchez A, Khan J, Polak MA, Glass JD. 2004. Amyotrophic lateral sclerosis is a distal axonopathy: evidence in mice and man. Exp Neurol 185(2):232-40.

Flicek P, Aken BL, Beal K, Ballester B, Caccamo M, Chen Y, Clarke L, Coates G, Cunningham F, Cutts T and others. 2008. Ensembl 2008. Nucleic Acids Res 36(Database issue):D707-14.

Gardina PJ, Clark TA, Shimada B, Staples MK, Yang Q, Veitch J, Schweitzer A, Awad T, Sugnet C, Dee S and others. 2006. Alternative splicing and differential gene expression in colon cancer detected by a whole genome exon array. BMC Genomics 7:325.

Gasteiger E, Gattiker A, Hoogland C, Ivanyi I, Appel RD, Bairoch A. 2003. ExPASy: The proteomics server for in-depth protein knowledge and analysis. Nucleic Acids Res 31(13):3784-8. 
Gibson GE, Starkov A, Blass JP, Ratan RR, Beal MF. 2009. Cause and consequence: Mitochondrial dysfunction initiates and propagates neuronal dysfunction, neuronal death and behavioral abnormalities in age-associated neurodegenerative diseases. Biochim Biophys Acta. 1802(1):122-34

Giger RJ, Cloutier JF, Sahay A, Prinjha RK, Levengood DV, Moore SE, Pickering S, Simmons D, Rastan S, Walsh FS and others. 2000. Neuropilin-2 is required in vivo for selective axon guidance responses to secreted semaphorins. Neuron 25(1):29-41.

Gitai Z, Yu TW, Lundquist EA, Tessier-Lavigne M, Bargmann CI. 2003. The netrin receptor UNC-40/DCC stimulates axon attraction and outgrowth through enabled and, in parallel, Rac and UNC-115/AbLIM. Neuron 37(1):53-65.

Gurney ME, Pu H, Chiu AY, Dal Canto MC, Polchow CY, Alexander DD, Caliendo J, Hentati A, Kwon YW, Deng HX and others. 1994. Motor neuron degeneration in mice that express a human $\mathrm{Cu}, \mathrm{Zn}$ superoxide dismutase mutation. Science 264(5166):1772-5.

Hinman MN, Lou H. 2008. Diverse molecular functions of Hu proteins. Cell Mol Life $\underline{\text { Sci } 65(20): 3168-81 .}$

Irizarry RA, Hobbs B, Collin F, Beazer-Barclay YD, Antonellis KJ, Scherf U, Speed TP. 2003. Exploration, normalization, and summaries of high density oligonucleotide array probe level data. Biostatistics 4(2):249-64.

Jaiswal MK, Keller BU. 2009. Cu/Zn superoxide dismutase typical for familial amyotrophic lateral sclerosis increases the vulnerability of mitochondria and perturbs Ca2+ homeostasis in SOD1G93A mice. Mol Pharmacol 75(3):47889. 
Jaiswal MK, Zech WD, Goos M, Leutbecher C, Ferri A, Zippelius A, Carri MT, Nau

R, Keller BU. 2009. Impairment of mitochondrial calcium handling in a mtSOD1 cell culture model of motoneuron disease. BMC Neurosci 10:64.

Jiang YM, Yamamoto M, Kobayashi Y, Yoshihara T, Liang Y, Terao S, Takeuchi H, Ishigaki S, Katsuno M, Adachi H and others. 2005. Gene expression profile of spinal motor neurons in sporadic amyotrophic lateral sclerosis. Ann Neurol 57(2):236-51.

Jokic N, Gonzalez de Aguilar JL, Dimou L, Lin S, Fergani A, Ruegg MA, Schwab ME, Dupuis L, Loeffler JP. 2006. The neurite outgrowth inhibitor Nogo-A promotes denervation in an amyotrophic lateral sclerosis model. EMBO Rep $7(11): 1162-7$

Kaneko S, Iwanami A, Nakamura M, Kishino A, Kikuchi K, Shibata S, Okano HJ, Ikegami T, Moriya A, Konishi O and others. 2006. A selective Sema3A inhibitor enhances regenerative responses and functional recovery of the injured spinal cord. Nat Med 12(12):1380-9.

Kania A, Johnson RL, Jessell TM. 2000. Coordinate roles for LIM homeobox genes in directing the dorsoventral trajectory of motor axons in the vertebrate limb. Cell 102(2):161-73.

Karni R, de Stanchina E, Lowe SW, Sinha R, Mu D, Krainer AR. 2007. The gene encoding the splicing factor SF2/ASF is a proto-oncogene. Nat Struct Mol Biol 14(3):185-93.

Lagier-Tourenne C, Cleveland DW. 2009. Rethinking ALS: the FUS about TDP-43. Cell 136(6):1001-4.

Leprince C, Le Scolan E, Meunier B, Fraisier V, Brandon N, De Gunzburg J, Camonis J. 2003. Sorting nexin 4 and amphiphysin 2, a new partnership 
between endocytosis and intracellular trafficking. J Cell Sci 116(Pt 10):1937-

48.

Lesnick TG, Sorenson EJ, Ahlskog JE, Henley JR, Shehadeh L, Papapetropoulos S, Maraganore DM. 2008. Beyond Parkinson disease: amyotrophic lateral sclerosis and the axon guidance pathway. PLoS One 3(1):e1449.

Licatalosi DD, Darnell RB. 2006. Splicing regulation in neurologic disease. Neuron 52(1):93-101.

Lin H, Zhai J, Schlaepfer WW. 2005. RNA-binding protein is involved in aggregation of light neurofilament protein and is implicated in the pathogenesis of motor neuron degeneration. Hum Mol Genet 14(23):3643-59.

Magrane J, Manfredi G. 2009. Mitochondrial function, morphology, and axonal transport in amyotrophic lateral sclerosis. Antioxid Redox Signal. 11(7):1615$\underline{26 .}$

Maracchioni A, Totaro A, Angelini DF, Di Penta A, Bernardi G, Carri MT, Achsel T. 2007. Mitochondrial damage modulates alternative splicing in neuronal cells: implications for neurodegeneration. J Neurochem 100(1):142-53.

Mattiazzi M, D'Aurelio M, Gajewski CD, Martushova K, Kiaei M, Beal MF, Manfredi G. 2002. Mutated human SOD1 causes dysfunction of oxidative phosphorylation in mitochondria of transgenic mice. J Biol Chem 277(33):29626-33.

Munch C, Ebstein M, Seefried U, Zhu B, Stamm S, Landwehrmeyer GB, Ludolph AC, Schwalenstocker B, Meyer T. 2002. Alternative splicing of the 5'sequences of the mouse EAAT2 glutamate transporter and expression in a transgenic model for amyotrophic lateral sclerosis. J Neurochem 82(3):594603. 
1

2

3

4

5

6

7

8

9

10

11

12

13

14

15

16

17

18

19

20

21

22

23

24

25

26

27

28

29

30

31

32

33

34

35

36

37

38

39

40

41

42

43

44

45

46

47

48

49

50

51

52

53

54

55

56

57

58

59

60

Nguyen KT, Garcia-Chacon LE, Barrett JN, Barrett EF, David G. 2009. The Psi(m) depolarization that accompanies mitochondrial $\mathrm{Ca} 2+$ uptake is greater in mutant SOD1 than in wild-type mouse motor terminals. Proc Natl Acad Sci U S A 106(6):2007-11.

Nicot AS, Toussaint A, Tosch V, Kretz C, Wallgren-Pettersson C, Iwarsson E, Kingston H, Garnier JM, Biancalana V, Oldfors A and others. 2007. Mutations in amphiphysin 2 (BIN1) disrupt interaction with dynamin 2 and cause autosomal recessive centronuclear myopathy. Nat Genet 39(9):1134-9.

O'Donnell M, Chance RK, Bashaw GJ. 2009. Axon growth and guidance: receptor regulation and signal transduction. Annu Rev Neurosci 32:383-412.

Okoniewski MJ, Yates T, Dibben S, Miller CJ. 2007. An annotation infrastructure for the analysis and interpretation of Affymetrix exon array data. Genome Biol 8(5):R79.

Olsson PA, Bornhauser BC, Korhonen L, Lindholm D. 2000. Neuronal expression of the ERM-like protein MIR in rat brain and its localization to human chromosome 6. Biochem Biophys Res Commun 279(3):879-83.

Olsson PA, Korhonen L, Mercer EA, Lindholm D. 1999. MIR is a novel ERM-like protein that interacts with myosin regulatory light chain and inhibits neurite outgrowth. J Biol Chem 274(51):36288-92.

Pan Q, Shai O, Misquitta C, Zhang W, Saltzman AL, Mohammad N, Babak T, Siu H, Hughes TR, Morris QD and others. 2004. Revealing global regulatory features of mammalian alternative splicing using a quantitative microarray platform. Mol Cell 16(6):929-41. 
Pant S, Sharma M, Patel K, Caplan S, Carr CM, Grant BD. 2009. AMPH1/Amphiphysin/Bin1 functions with RME-1/Ehd1 in endocytic recycling. Nat Cell Biol 11(12):1399-410.

Pantelidou M, Zographos SE, Lederer CW, Kyriakides T, Pfaffl MW, Santama N. 2007. Differential expression of molecular motors in the motor cortex of sporadic ALS. Neurobiol Dis 26(3):577-89.

Perlson E, Jeong GB, Ross JL, Dixit R, Wallace KE, Kalb RG, Holzbaur EL. 2009. A switch in retrograde signaling from survival to stress in rapid-onset neurodegeneration. J Neurosci 29(31):9903-17.

Pizzasegola C, Caron I, Daleno C, Ronchi A, Minoia C, Carri MT, Bendotti C. 2009. Treatment with lithium carbonate does not improve disease progression in two different strains of SOD1 mutant mice. Amyotroph Lateral Scler 10(4):221-8.

Polleux F, Ince-Dunn G, Ghosh A. 2007. Transcriptional regulation of vertebrate axon guidance and synapse formation. Nat Rev Neurosci 8(5):331-40.

Pun S, Santos AF, Saxena S, Xu L, Caroni P. 2006. Selective vulnerability and pruning of phasic motoneuron axons in motoneuron disease alleviated by CNTF. Nat Neurosci 9(3):408-19.

Robertson J, Doroudchi MM, Nguyen MD, Durham HD, Strong MJ, Shaw G, Julien JP, Mushynski WE. 2003. A neurotoxic peripherin splice variant in a mouse model of ALS. J Cell Biol 160(6):939-49.

Robinow S, Campos AR, Yao KM, White K. 1988. The elav gene product of Drosophila, required in neurons, has three RNP consensus motifs. Science 242(4885):1570-2.

Rothstein JD. 2009. Current hypotheses for the underlying biology of amyotrophic lateral sclerosis. Ann Neurol 65 Suppl 1:S3-9. 
Sanges R, Cordero F, Calogero RA. 2007. oneChannelGUI: a graphical interface to Bioconductor tools, designed for life scientists who are not familiar with $\mathrm{R}$ language. Bioinformatics 23(24):3406-8.

Schmidt ER, Pasterkamp RJ, van den Berg LH. 2009. Axon guidance proteins: novel therapeutic targets for ALS? Prog Neurobiol 88(4):286-301.

Shi L, Fu WY, Hung KW, Porchetta C, Hall C, Fu AK, Ip NY. 2007. Alpha2chimaerin interacts with EphA4 and regulates EphA4-dependent growth cone collapse. Proc Natl Acad Sci U S A 104(41):16347-52.

Shi P, Gal J, Kwinter DM, Liu X, Zhu H. 2010. Mitochondrial dysfunction in amyotrophic lateral sclerosis. Biochim Biophys Acta 1802(1):45-51.

Smyth GK. 2004. Linear models and empirical bayes methods for assessing differential expression in microarray experiments. Stat Appl Genet Mol Biol 3:Article3.

Strom AL, Gal J, Shi P, Kasarskis EJ, Hayward LJ, Zhu H. 2008. Retrograde axonal transport and motor neuron disease. J Neurochem 106(2):495-505.

Strong MJ. 2009. The evidence for altered RNA metabolism in amyotrophic lateral sclerosis (ALS). J Neurol Sci 288(1-2):1-12.

Struckhoff EC, Lundquist EA. 2003. The actin-binding protein UNC-115 is an effector of Rac signaling during axon pathfinding in C. elegans. Development 130(4):693-704.

Stumm R, Hollt V. 2007. CXC chemokine receptor 4 regulates neuronal migration and axonal pathfinding in the developing nervous system: implications for neuronal regeneration in the adult brain. J Mol Endocrinol 38(3):377-82.

Sugimori M, Nagao M, Bertrand N, Parras CM, Guillemot F, Nakafuku M. 2007. Combinatorial actions of patterning and HLH transcription factors in the 
spatiotemporal control of neurogenesis and gliogenesis in the developing spinal cord. Development 134(8):1617-29.

Takei K, Slepnev VI, Haucke V, De Camilli P. 1999. Functional partnership between amphiphysin and dynamin in clathrin-mediated endocytosis. Nat Cell Biol 1(1):33-9.

Tomiyama M, Rodriguez-Puertas R, Cortes R, Pazos A, Palacios JM, Mengod G. 2002. Flip and flop splice variants of AMPA receptor subunits in the spinal cord of amyotrophic lateral sclerosis. Synapse 45(4):245-9.

Volkening K, Leystra-Lantz C, Strong MJ. 2009. Human low molecular weight neurofilament (NFL) mRNA interacts with a predicted p190RhoGEF homologue (RGNEF) in humans. Amyotroph Lateral Scler:1-7.

Westfall PH YS. 1993. Resampling-based multiple testing: examples and Materials and Methods for p-value adjustment. New York: John Wiley \& Sons.

Wolman MA, Liu Y, Tawarayama H, Shoji W, Halloran MC. 2004. Repulsion and attraction of axons by semaphorin3D are mediated by different neuropilins in vivo. J Neurosci 24(39):8428-35.

Yamamoto ML, Clark TA, Gee SL, Kang JA, Schweitzer AC, Wickrema A, Conboy JG. 2009. Alternative pre-mRNA splicing switches modulate gene expression in late erythropoiesis. Blood 113(14):3363-70.

Yates T, Okoniewski MJ, Miller CJ. 2008. X:Map: annotation and visualization of genome structure for Affymetrix exon array analysis. Nucleic Acids Res 36(Database issue):D780-6.

Yonekawa Y, Harada A, Okada Y, Funakoshi T, Kanai Y, Takei Y, Terada S, Noda T, Hirokawa N. 1998. Defect in synaptic vesicle precursor transport and 
1

2

3

4

5

6

7

8

9

10

11

12

13

14

15

16

17

18

19

20

21

22

23

24

25

26

27

28

29

30

31

32

33

34

35

36

37

38

39

40

41

42

43

44

45

46

47

48

49

50

51

52

53

54

55

56

57

58

59

60

neuronal cell death in KIF1A motor protein-deficient mice. J Cell Biol 141(2):431-41.

Yoo S, van Niekerk EA, Merianda TT, Twiss JL. 2009. Dynamics of axonal mRNA transport and implications for peripheral nerve regeneration. Exp Neurol. 223(1):19-27.

Zou YR, Kottmann AH, Kuroda M, Taniuchi I, Littman DR. 1998. Function of the chemokine receptor CXCR4 in haematopoiesis and in cerebellar development. Nature 393(6685):595-9. 


\section{Tables}

Table 1. Molecular and Cellular Functions affected by PQ treatment.

Name

p-value

Cellular Growth and Proliferation

$1.33 \mathrm{E}-18-1.01 \mathrm{E}-03$

Molecules

Cell Death

$6.28 \mathrm{E}-17-1.03 \mathrm{E}-03$

435

Cell Cycle

$1.62 \mathrm{E}-15-9.86 \mathrm{E}-04$

368

Cellular Development

$6.75 \mathrm{E}-12-1.01 \mathrm{E}-03$

213

Cellular Movement

4.66E-09 - 1.02E-03

312

240

Table 2. Top Canonical Pathways affected by PQ treatment.

\begin{tabular}{lcc} 
Name & p-value & Ratio \\
\hline p53 Signaling & $6.77 \mathrm{E}-04$ & $22 / 87$ \\
Circadian Rhythm Signaling & $1.43 \mathrm{E}-03$ & $10 / 32$ \\
Hepatic Fibrosis / Hepatic Stellate Cell Activation & $3.02 \mathrm{E}-03$ & $22 / 131$ \\
Neurotrophin/TRK Signaling & $3.24 \mathrm{E}-03$ & $13 / 73$ \\
NRF2-mediated Oxidative Stress Response & $3.37 \mathrm{E}-03$ & $29 / 180$
\end{tabular}

Table 3. Functions affected by the expression of the SOD1(G93A) protein.

Name

p-value

Molecules

Cellular Movement

6.30E-09- 1.13E-02 40

Cellular Assembly and Organization

9.44E-07 - 1.13E-02

25

Cell Cellular growth and Proliferation

$2.72 \mathrm{E}-06-1.18 \mathrm{E}-02$

57

\begin{tabular}{lcc}
\hline Nervous System Development and Function & $6.30 \mathrm{E}-09-1.18 \mathrm{E}-02$ & 49 \\
\hline Genetic Disorders & $1.78 \mathrm{E}-07-1.13 \mathrm{E}-02$ & 67 \\
Neurological Diseases & $1.78 \mathrm{E}-07-1.13 \mathrm{E}-02$ & 46 \\
Psychological Diseases & $1.78 \mathrm{E}-07-5.87 \mathrm{E}-03$ & 20
\end{tabular}

Table 4. Genes related to the "Nervous System Differentiation and Function" Category

\begin{tabular}{|c|c|c|}
\hline SYMBOL & DESCRIPTION & Function annotation \\
\hline$A D O R A 2 A$ & adenosine A2a receptor & $\begin{array}{l}\text { growth of neuritis, } \\
\text { synaptic transmission }\end{array}$ \\
\hline$A P B A 1$ & EPH receptor A6 & $\begin{array}{c}\text { exocytosis of } \\
\text { synaptic vesicles }\end{array}$ \\
\hline$A S C L 1$ & $\begin{array}{l}\text { achaete-scute complex homolog } 1 \\
\text { (Drosophila) }\end{array}$ & neurogenesis \\
\hline$B M P 7$ & bone morphogenetic protein 7 & neurogenesis \\
\hline$B V E S$ & blood vessel epicardial substance & $\begin{array}{l}\text { regeneration of } \\
\text { satellite cells }\end{array}$ \\
\hline C4ORF6 & chromosome 4 open reading frame 6 & neurogenesis \\
\hline CABLES1 & Cdk5 and Abl enzyme substrate 1 & neurogenesis \\
\hline$C D O N$ & Cdon homolog (mouse) & $\begin{array}{l}\text { differentiation of } \\
\text { neurons }\end{array}$ \\
\hline
\end{tabular}


CHRDL1 chordin-like 1

differentiation of neurons

CHRM2 cholinergic receptor, muscarinic 2, cardiac

$C L U$

CNTN4 contactin 4

DLX5

DPYSL5

ELAVL2

GATA2

INHBA

KIT

LIFR

MPPED2

$N M U$

NNAT

NQO1

NTRK1

PBX1

PLXNA4

PTPRM

SEMA3D

SERPINII

SERPINE2

SIX3

ST8SIA2

SYT2 clusterin

distal-less homeobox 5

neurogenesis

morphogenesis of neurites neurogenesis neurogenesis neurogenesis

differentiation of neurons

differentiation of neurons neurogenesis

neurogenesis

survival of nervous tissue

growth of neurites differentiation of neurons

neurogenesis

metallophosphoesterase domain containing 2 neuromedin $\mathrm{U}$ neuronatin

NAD(P)H dehydrogenase, quinone 1 neurotrophic tyrosine kinase, receptor, type 1

pre B-cell leukemia transcription factor 1

plexin A4

protein tyrosine phosphatase, receptor type, $\mathrm{M}$

sema domain, immunoglobulin domain (Ig), short basic domain, secreted, (semaphorin) 3D serpin peptidase inhibitor, clade I (neuroserpin), member 1 serine (or cysteine) peptidase inhibitor, clade I, member 2 sine oculis-related homeobox 3 homolog (Drosophila) ST8 alpha-N-acetyl-neuraminide alpha-2,8sialyltransferase 2 [Mus musculus] synaptotagmin II synaptic transmission development of nervous system synaptic transmission neurogenesis, survival of nervous tissue

differentiation of neurons neurogenesis growth of neurites neurogenesis development of nervous system integration of sensorimotor cortex generation of neurons neurogenesis exocytosis of synaptic vesicles 
Table 5. Molecular and Cellular Functions affected by putative ASEs in paraquat-treated SH-SY5Y cells.

Name

p-value

Molecules

Cell Death

1.69E-18 - 1.81E-03

126

Cellular Growth and Proliferation

$1.25 \mathrm{E}-15-1.79 \mathrm{E}-03$

137

Cell Cycle

$1.09 \mathrm{E}-13-1.90 \mathrm{E}-03$

77

Cellular Development

$1.21 \mathrm{E}-12-1.67 \mathrm{E}-03$

67

Cellular Movement

$2.08 \mathrm{E}-09-2.17 \mathrm{E}-04$

90

Table 6. Top Canonical Pathways affected by putative ASEs in SOD1(G93A) SHSY5Y cells.

Name

Calcium Signaling

\begin{tabular}{cc} 
p-value & Ratio \\
\hline $1.81 \mathrm{E}-03$ & $7 / 206$
\end{tabular}

cAMP-mediated Signaling

$3.65 \mathrm{E}-03 \quad 6 / 162$

G-Protein Coupled Receptor Signaling

Neuropathic Pain Signaling in Dorsal Horn Neurons

$3.89 \mathrm{E}-03 \quad 7 / 217$

Cell Cycle:G1/S Checkpoint Regulation

$1.49 \mathrm{E}-02 \quad 4 / 104$

$1.56 \mathrm{E}-02 \quad 3 / 59$ 
A

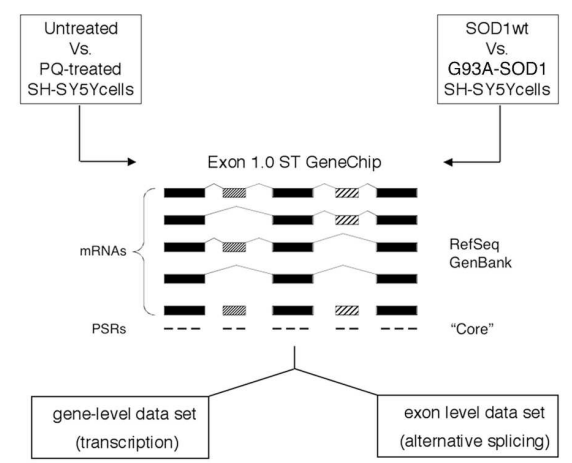

C

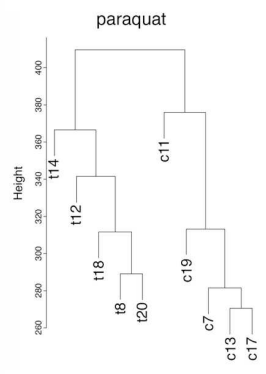

B
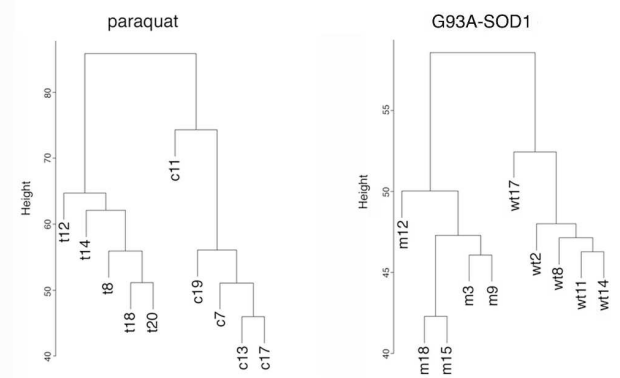

D



Figure 1.

Whole genome, splicing-sensitive microarray analysis of the cellular response to mitochondrial dysfunction.

$180 \times 141 \mathrm{~mm}(600 \times 600 \mathrm{DPI})$

John Wiley \& Sons, Inc. 


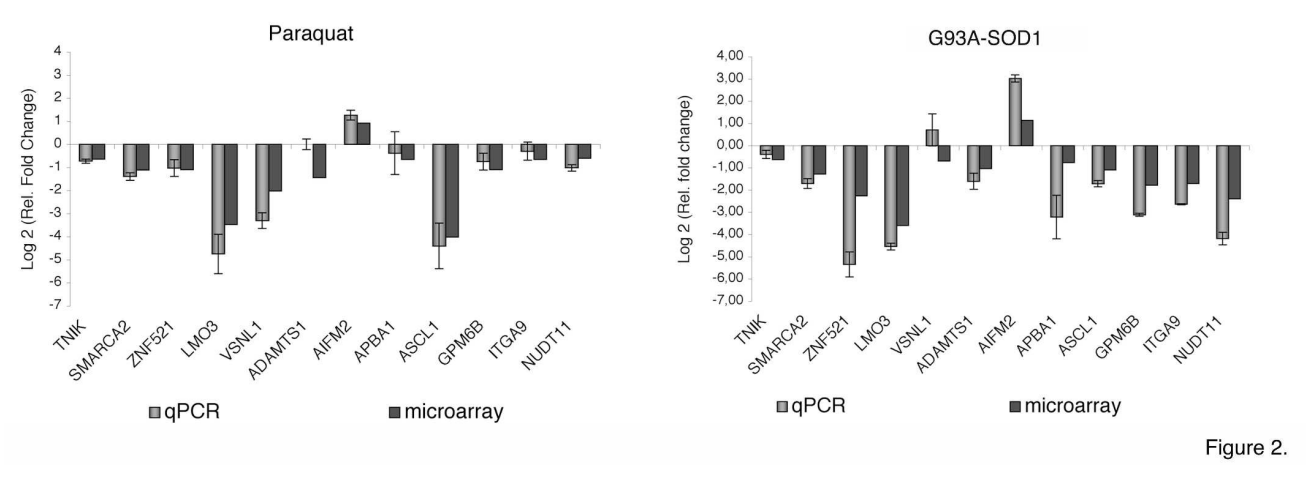

Experimental validation of the gene-level microarray data in SH-SY5Y cells. $180 \times 62 \mathrm{~mm}(600 \times 600 \mathrm{DPI})$

John Wiley \& Sons, Inc. 
A

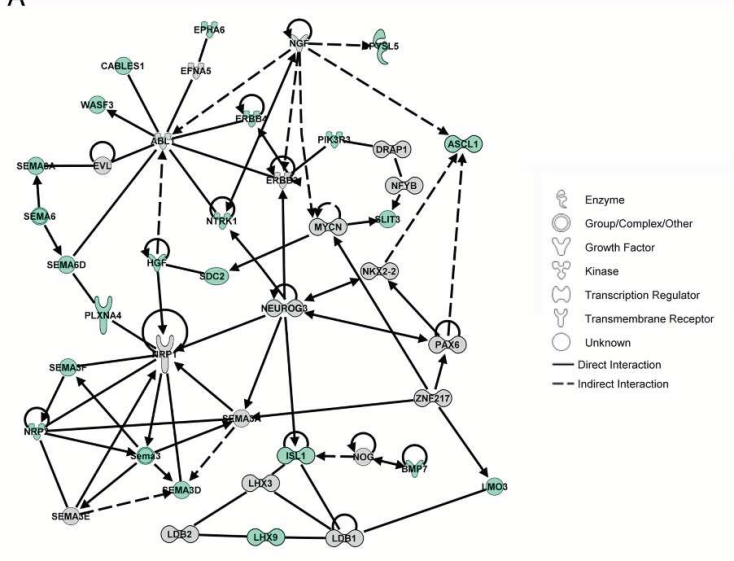

B

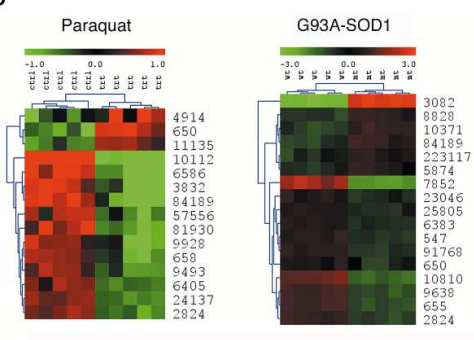

D

C
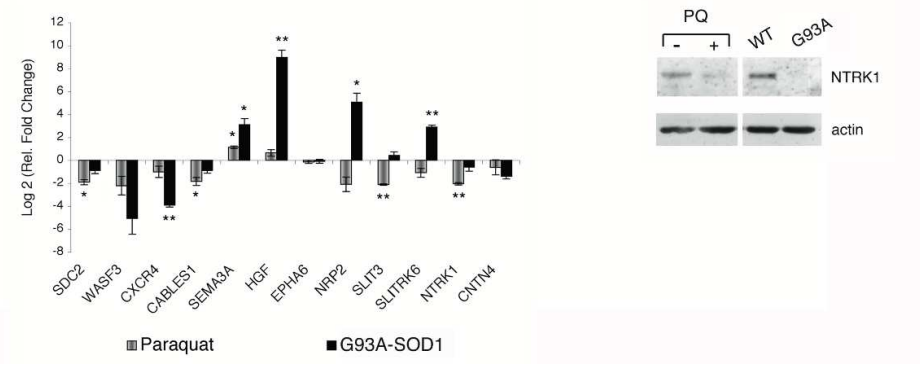

E

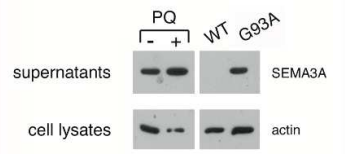

Mitochondrial dysfunction alters expression and splicing of genes involved in axon growth and guidance.

$270 \times 211 \mathrm{~mm}(600 \times 600 \mathrm{DPI})$

John Wiley \& Sons, Inc. 
A

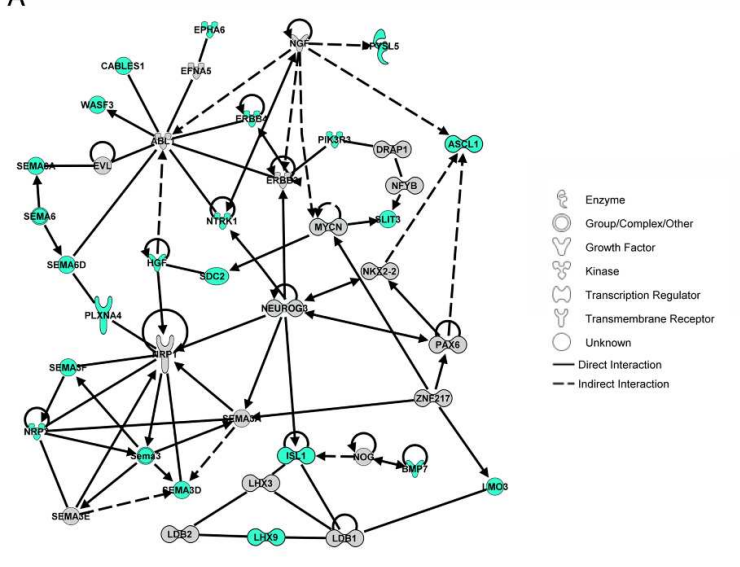

C

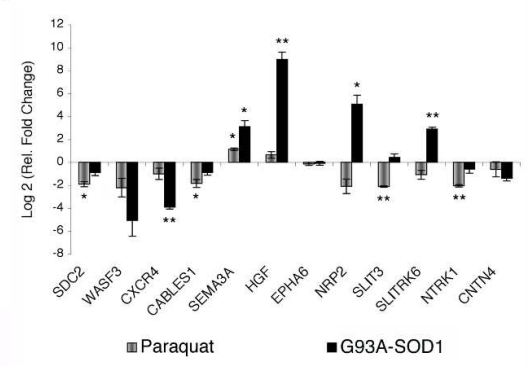

B

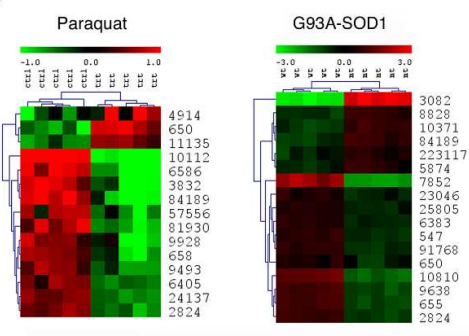

D

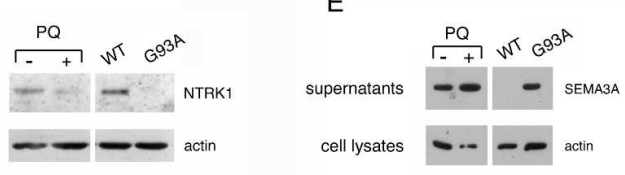

Mitochondrial dysfunction alters expression and splicing of genes involved in axon growth and guidance.

$270 \times 211 \mathrm{~mm}(600 \times 600 \mathrm{DPI})$

37

38

39

40

41

42

43

44

45

46

47

48

49

50

51

52

53

54

55

56

57

58

59

60

John Wiley \& Sons, Inc. 
A

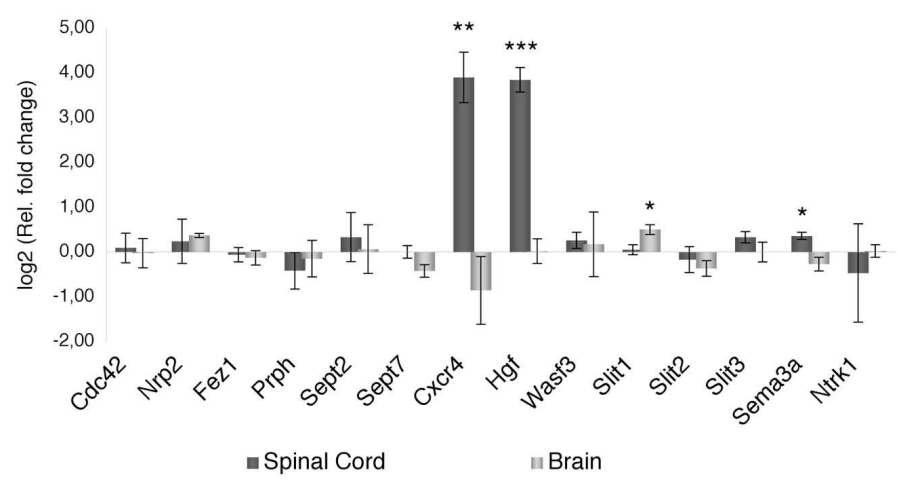

B
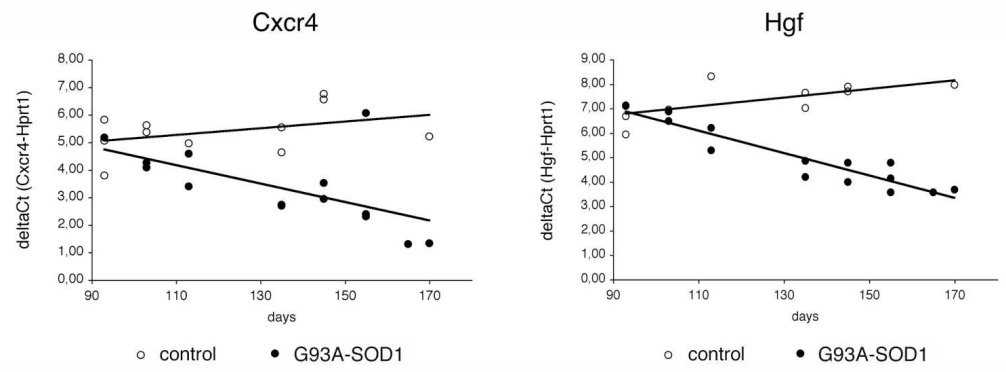

C


Figure 4.

Analysis of the expression of genes involved in neuritogenesis in the G93A-Sod1 mouse model. $135 \times 195 \mathrm{~mm}(600 \times 600 \mathrm{DPI})$

John Wiley \& Sons, Inc. 
A

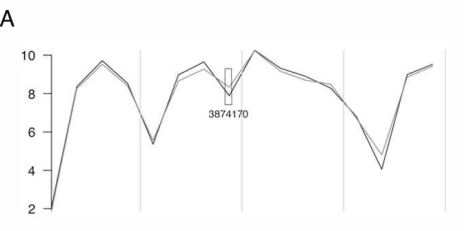

B

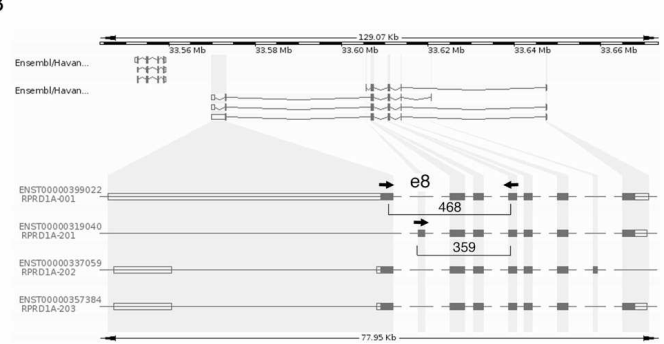

C

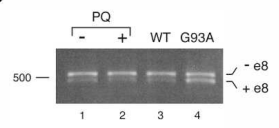

D
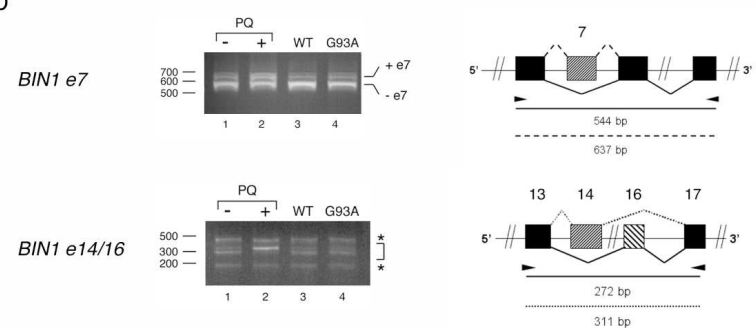

E

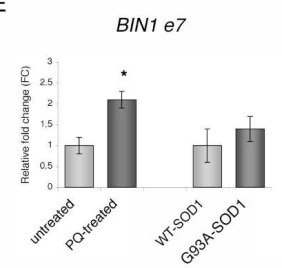

F

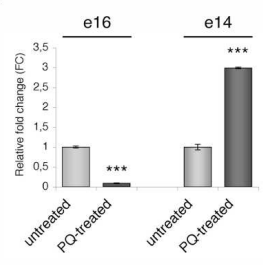

G

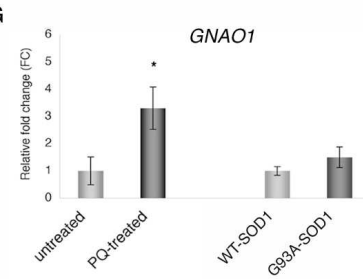

Figure 5

Experimental validation of the alternative internal exons identified by microarray analysis. $240 \times 209 \mathrm{~mm}(600 \times 600$ DPI $)$

John Wiley \& Sons, Inc. 
A

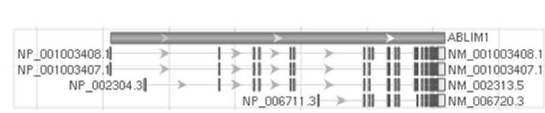

C

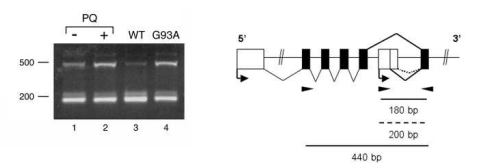

E

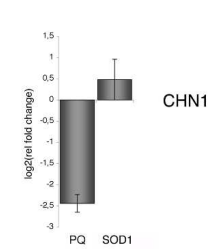

F



Experimental validation of the alternative first exons identified by microarray analysis. $323 \times 269 \mathrm{~mm}(600 \times 600 \mathrm{DPI})$

John Wiley \& Sons, Inc. 


\section{Supporting Results}

$P Q$ treatment inhibits cell proliferation and modifies alternative pre-mRNA splicing in SH-SY5Y neuroblastoma cells

PQ is a neurotoxic herbicide that induces Parkinsonian features in animal models (for review see (Cicchetti, et al., 2009).). The chemical structure of PQ is similar to the known dopaminergic neurotoxin, N-methyl-4-phenylpridinium ion (MPP+), the active metabolite of MPTP. Thus, it belongs to the class of redox cycling compounds capable of inducing mitochondrial damage, increasing reactive oxygen species (ROS) production and oxidative stress (Birney, et al., 2007; Castello, et al., 2007).

Concentration-response time course studies were conducted to determine an effective range for PQ upon SH-SY5Y cell proliferation. We used the MTT assay, which is mostly based on the activity of a mitochondrial dehydrogenase and therefore is largely used as a measure of mitochondrial activity. Based on the results shown in Figure S1A, we decided to perform subsequent experiments with cells exposed to $0.75 \mathrm{mM}$ PQ for $18 \mathrm{~h}$.

We next evaluated alternative splicing changes in these conditions. We assayed the AS pattern of APAF1, BCL2L1 (BCL-X), CASP2, and CASP9 (Supp.Figure S1B) that we had described in (Maracchioni, et al., 2007). Consistent with our previous data, even a treatment with lower PQ concentration and for a shorter incubation time induced a change in the alternative splicing pattern of APAF1, CASP9, and SMN1 but not of $B C L 2 L 1$ (Supp. Figure S1C).

\section{Experimental validation of the differential expression data for the $P Q$ experiment}

Pathway analysis of microarray data identified Cellular Growth and Proliferation, Cell Death, and Cell Cycle as the biological functions that are most affected by PQ. 
Thus, we first characterized the cell cycle distribution of PQ-treated cells. Flowcytometric analyses of sub-confluent, treated cells showed an increase in the G1- and a decrease in the S-phase populations when compared to untreated control cells (Figure S1A). This observation was consistent with the downregulation of cyclin A2 (CCNA2) and cyclin E2 (CCNE2) required for S/G2 progression, and of cyclin B (CCNB1), required for $\mathrm{G} 2 / \mathrm{M}$ transition, as well as with the upregulation of $C D K N 3$, a CDK2-phosphatase, and of p21 (CDKN1B), as detected by microarray analysis (Supp. Table S1). Western blot analysis confirmed the downregulation of cyclin A and cyclin B (Supp. Figure S1B). In addition, in treated cells we detected the presence of a subG1 population indicating that some cell death occurred upon incubation with PQ (data not shown). The induction of apoptosis was confirmed by Terminal deoxynucleotidyl transferase dUTP nick end-labeling (TUNEL) assays (Supp. Figure S1C). While a very low population was found in region 2 in the untreated control samples, treated cells exhibited a TUNEL-positive fraction of $\sim 20 \%$. Induction of apoptosis in a subset of the cells was further supported by the proteolytic cleavage of PARP a known caspase 1 substrate, observed by Western blotting (Supp. Figure S1D).

\section{Material and Methods \\ Assessment of cell viability}

Cell viability was assessed with the MTT colorimetric assay. The assay is based on the determination of the mitochondrial dehydrogenase activity that reduces 3-(4,5dimethylthiazol-2-yl)-2,5-diphenyl-tetrazolium bromide (MTT, Sigma-Aldrich). At day 0 , SH-SY5Y cells were plated at a density of $5 \times 10^{4}$ viable cells per well in 96well plates. The next day, cells were incubated for $24 \mathrm{~h}$ at $37^{\circ} \mathrm{C}$ in the presence of 
different concentrations of $\mathrm{PQ}$, or for different times in the presence of $0.75 \mathrm{mM}$ of PQ. Cells were then exposed to an MTT-containing solution (1 mg/ml in PBS) for $4 \mathrm{~h}$ at $37^{\circ} \mathrm{C}$ and subsequently treated with SDS in dimethylformamide o.n. Absorbance was read at 550 and $655 \mathrm{~nm}$ with a Multiscan EX (Thermo Fisher Scientific Inc.). Cytotoxicity was evaluated as percentage of the control untreated with PQ.

\section{Cell cycle analysis}

SH-SY5Y neuroblastoma cells were seeded at 1,2x106 cells per well in $60 \mathrm{~mm}$ dish, and the day after were treated with $0,75 \mathrm{mM}$ of PQ for 18 hours. Then untreated and treated cells, both attached and detached populations, were collected and fixed in 70\% ethanol in PBS and kept at $4{ }^{\circ} \mathrm{C}$ before staining. Fixed cells were then washed with cold PBS and resuspended in $1 \mathrm{~mL}$ of a solution containing $10 \mathrm{ug} / \mathrm{ml}$ of propidium iodide (PI) in PBS and $7 \mu 1$ RNAse $3 \mathrm{mg} / \mathrm{ml}$ in water, and stained overnight at $4^{\circ} \mathrm{C}$ in the dark. DNA analysis was done on at least 30000 cells for each sample by the FACSCalibur (BD Biosciences - CA USA) and the data were analyzed using ModFIT LTsoftware (Verity Software House - ME USA). Experiment was performed in triplicate.

\section{TUNEL assay}

Apoptosis was measured using the TUNEL assay kit (Roche Diagnostics, Basel, Switzerland) following the manufacturers' instruction for dual parameter flow cytometry. Analysis was performed on a FACSCalibur (BD Biosciences - CA USA) and the data were analyzed using Summit 4.3 software (Coulter - CA USA). 


\section{Immunoblotting}

$1.5 \times 10^{6}$ cells were plated on $\mathrm{p} 60 \mathrm{~mm}$ Petri dishes. After treatment with paraquat, cells were rinsed in ice cold PBS and lysed in $150 \square 1$ low salt buffer (10 mM Hepes pH 7.4, $42 \mathrm{mM} \mathrm{KCl}, 5 \mathrm{mM} \mathrm{MgCl} 2,0.5 \%$ CHAPS, $1 \mathrm{mM} \mathrm{DTT,} \mathrm{1mM} \mathrm{PMSF,} 1 \square \mathrm{g} / \mathrm{ml}$ leupeptin). After centrifugation at $20000 \mathrm{~g}$, nuclei were resuspended in $50 \square 1$ high salt buffer (50mM Tris- $\mathrm{HCl} \mathrm{pH} 7.5,400 \mathrm{mM} \mathrm{NaCl}, 1 \mathrm{mM}$ EDTA, $1 \%$ Triton X-100, 0.5\% NP-40, 10\% glycerol, 2mM DTT, 1mM PMSF, protease inhibitor cocktail. After 30' on ice, lysates were centrifuged at $20000 \mathrm{~g}$, supernatants were collected and analysed as nuclear fractions in Western blot with antibodies anti-cleaved PARP1 (Cell Signal) and anti-LaminB (Santa Cruz).

For the analysis of cyclin expression cell monolayers were washed twice with ice cold PBS and lysed on the tissue culture dish by addition of ice-cold lysis buffer $(50 \mathrm{mM}$ Tris-HCl, $\mathrm{pH} 7.5,150 \mathrm{mM} \mathrm{NaCl}$, and $1 \% \mathrm{NP}-40$, and complete protease inhibitor cocktail (Roche Diagnostics). Anti-cyclin A, and anti-cyclin B, were from BD Biosciences, (Pharmingen).

\section{Quality control for RNA and Arrays}

RNA quantity was assessed by Ribogreen (Invitrogen). Total RNA integrity was assessed using a Bioanalyzer (Agilent) and the RNA Integrity Number (RIN) was calculated. RIN values ranged from 8.7 to 10 with a media of 9.6 For target preparation $1.5 \mu \mathrm{g}$ of total RNA and the GeneChip WT cDNA Amplification kit (Affymetrix) were used. Amounts of ssDNA obtained ranged from 7 to $10 \mu \mathrm{g}$ with a media of $8.8 \mu \mathrm{g}$. ssDNA before and following fragmentation was analysed using a Bioanalyzer (Agilent). Typical ssDNA fragments have a size range from 40-70 nt. 
Hybridization to the Standard array: Fragmented ssDNAs were hybridized to the standard arrays for 17 hours at $45^{\circ} \mathrm{C}$; the arrays were then washed and stained using the fluidics station and then scanned using GeneChip Scanner 3000. The images were analyzed using Command Console and comparison analyses were carried out according to the instructions provided by Affymetrix. Standard array quality controls are shown in Supp. Figures S3-S6.

The "negative control", "positive control" and "all probe set" metrics are useful in understanding the overall quality of the data from each chip. Metrics based on these categories will reflect the quality of the whole experiment (RNA, target prep, chip, hybridization, scanning, and gridding) and the nature of the data being used in downstream statistical analysis. 

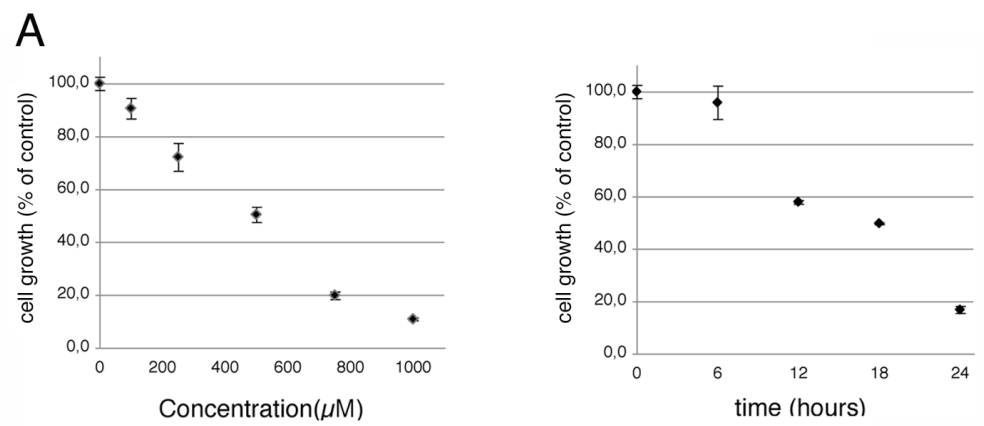

B

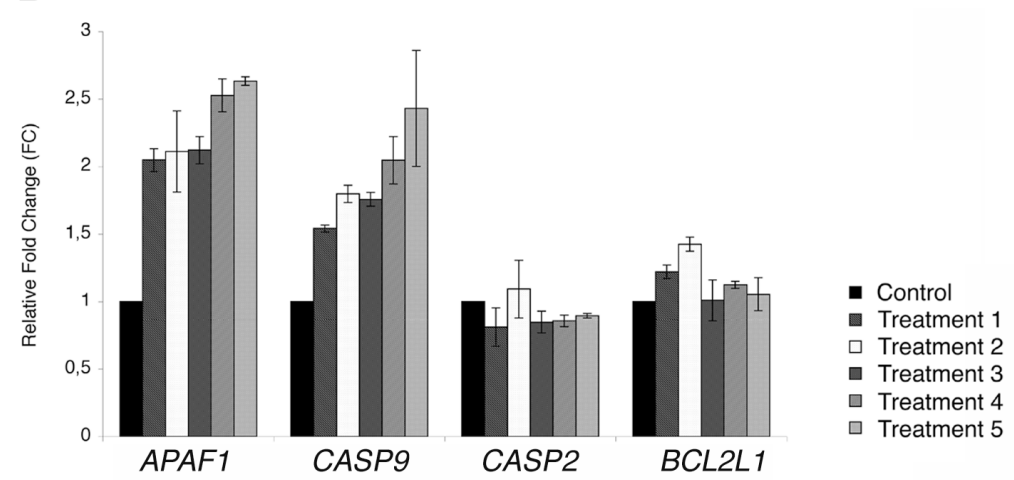

C



APAF1

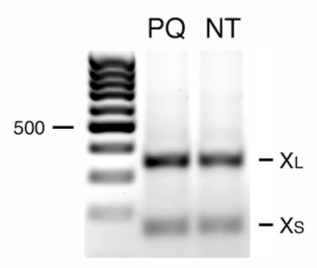

BCL2L1

Figure S1

Figure S1. Treatment with paraquat inhibits cell proliferation and modifies alternative pre-mRNA splicing in SH-SY5Y neuroblastoma cells.

A. Effect of PQ on cell growth. Dose- (left panel) and time- (right panel) dependent effect of PQ on SH-SY5Y cells. Exponentially dividing cells were treated with increasing concentrations of PQ for $24 \mathrm{~h}$, or with $0,75 \mathrm{mM} \mathrm{PQ}$ for 
different times. Cell viability was determined using the MTT assay. The percentage of growth was calculated, with $100 \%$ representing control cells. The results are the means \pm standard error from duplicate experiments.

B. Alternative splicing analysis of specific mRNAs. In five independent experiments, SH-SY5Y cells were treated with $0.75 \mathrm{mM}$ PQ for $18 \mathrm{~h}$. Total RNA was extracted, and the alternatively spliced regions of the indicated mRNAs mRNAs were amplified by RT-PCR using primers that span the alternative exons. After separation the PCR products were quantified as described in Materials and methods. The bars show the average fold increase of the indicated isoform after PQ treatment; error bars indicate the standard error.

C. Agarose gel electrophoresis of APAF1 and BCL2L1 RT-PCR products. Specific bands are labelled on the right of each panel. Marker: 100-bp ladder. 
A

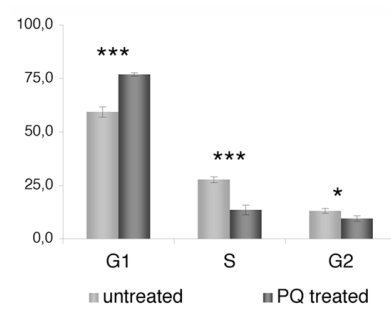

C

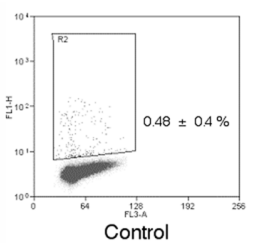

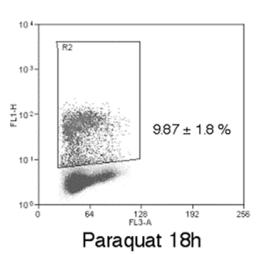

B



D

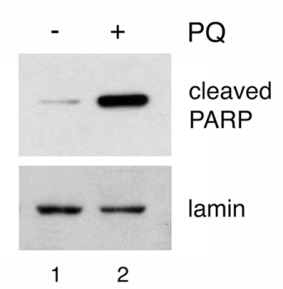

Figure S2

Figure S2. Experimental validation of the gene-level microarray data.

A. Analysis of cell cycle phase distribution of SH-SY5Y cells after treatment with $750 \mu \mathrm{M}$ PQ. Quantifications were performed by flow cytometry after 18 $\mathrm{h}$ of treatment on cells stained with propidium iodide. Data are means of three independent experiments; error bars show standard errors. Bars identified by three asterisks have a $\mathrm{p}$ value $\leq 0.001$ while those labelled with one asterisk have a $\mathrm{p}$ value $=0.01$ to 0.05 .

B. Western blot analysis for cyclin A and cyclin B performed on whole cell extracts prepared from untreated SH-SY5Y cells and treated with 0,75 mM PQ for $18 \mathrm{~h}$.

C. Representative dot plots of untreated control cells and cells treated with 0,75 $\mathrm{mM}$ PQ for $18 \mathrm{~h}$. Cells were stained by the fluorescence based TUNEL reaction and analysed by flow cytometry. The fluorescent cell populations in region 2 (R2) consist of apoptotic cells. 
D. Western blot analysis for cleaved PARP performed on whole cell extracts prepared from untreated SH-SY5Y cells and treated with $750 \mu \mathrm{M}$ PQ for $18 \mathrm{~h}$. 


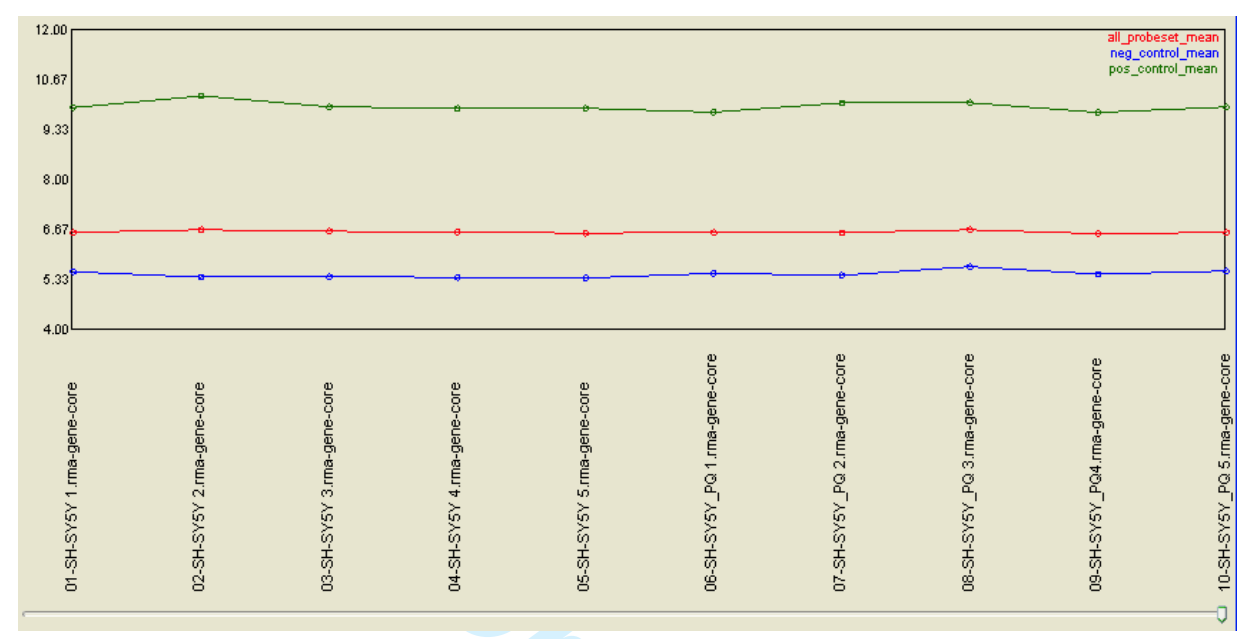

Figure S3. All probe sets, negative and positive controls signal intensities in PQ-

\section{treated SH-SY5Y cells experiment}

"All probe set" quality control metric: red line. It represents the intensity signal of all the probe sets analyzed.

"Neg control" quality control metric: blue line. It represents the intensity signal of the set of putative intron-based probe sets from putative housekeeping genes.

"Pos control" quality control metric: green line. It represents the intensity signal of the set of putative exon based probe sets from putative housekeeping genes. 
Figure S4. Positive vs Negative auc line graph in PQ-treated SH-SY5Y cells experiment.

Pos vs neg auc is the area under the curve (AUC) for a receiver operating characteristic (ROC) plot comparing signal values for the positive controls to the negative controls. The ROC curve is generated by evaluating how well the probe set signals separate the positive controls from the negative controls with the assumption that the negative controls are a measure of false positives and the positive controls are a measure of true positives. An AUC of 1 reflects perfect separation whereas as an AUC value of 0.5 would reflect no separation. In practice the expected value for this metric is tissue type specific and may be sensitive to the quality of the RNA sample. Values between 0.80 and 0.90 are typical.

"Pos vs neg auc" quality control metric: red line. 
Figure S5. “All probe sets", "negative " and "positive" control signal intensities in experiment performed in SOD1 wt vs SOD1(G93A) SH-SY5Y cells.

"All probe set" quality control metric: red line. It represents the intensity signal of all the probe sets analyzed. The quality metrics reported for this category are going to be driven by the main source of content in that particular analysis. Thus the metrics reported for this category will be the most representative of the quality of the data being used downstream. For a good set of arrays, this intensity value does not have to vary.

"Neg control" quality control metric: blue line. Pos control" quality control metric: green line. 


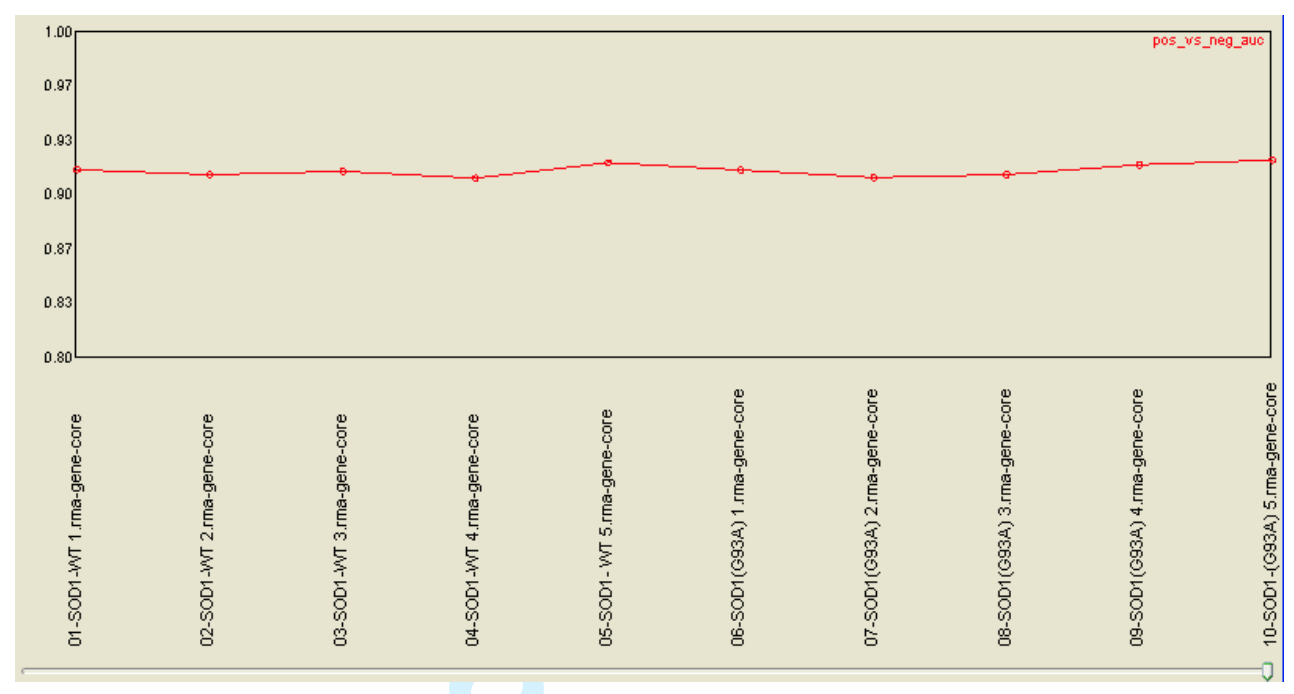

Figure S6. Positive vs. Negative AUC line graph in the experiment performed in

\section{SOD1 wt vs SOD1(G93A) SH-SY5Y cells..}

"Pos $v s$ neg auc "is the area under the curve (AUC) for a receiver operating characteristic (ROC) plot comparing signal values for the positive controls to the negative controls. The ROC curve is generated by evaluating how well the probe set signals separate the positive controls from the negative controls with the assumption that the negative controls are a measure of false positives and the positive controls are a measure of true positives. An AUC of 1 reflects perfect separation whereas as an AUC value of 0.5 would reflect no separation. Values between 0.80 and 0.90 are typical. "Pos $v s$ neg auc" quality control metric: red line.

Deleted: II
II
II
ReferencesII
Birney E, Stamatoyannopoulos JA, Dutta
A, Guigo R, Gingeras TR, Margulies EH,
Weng Z, Snyder M, Dermitzakis ET,
Thurman RE and others. 2007.
Identification and analysis of functional
elements in 1\% of the human genome by
the ENCODE pilot project. Nature
447(7146):799-816.II
Castello PR, Drechsel DA, Patel M.
2007. Mitochondria are a major source of
paraquat-induced reactive oxygen species
production in the brain. J Biol Chem
282(19):14186-93.II
Cicchetti F, Drouin-Ouellet J, Gross RE.
2009. Environmental toxins and
Parkinson's disease: what have we
learned from pesticide-induced animal
models? Trends Pharmacol Sci
30(9):475-83.II
II




\section{Supp. Table S6.Genes associated to Neurological Disorder, Axonal Guidance Signaling, and Neuritogenesis}

\section{Neurological Disosrders}

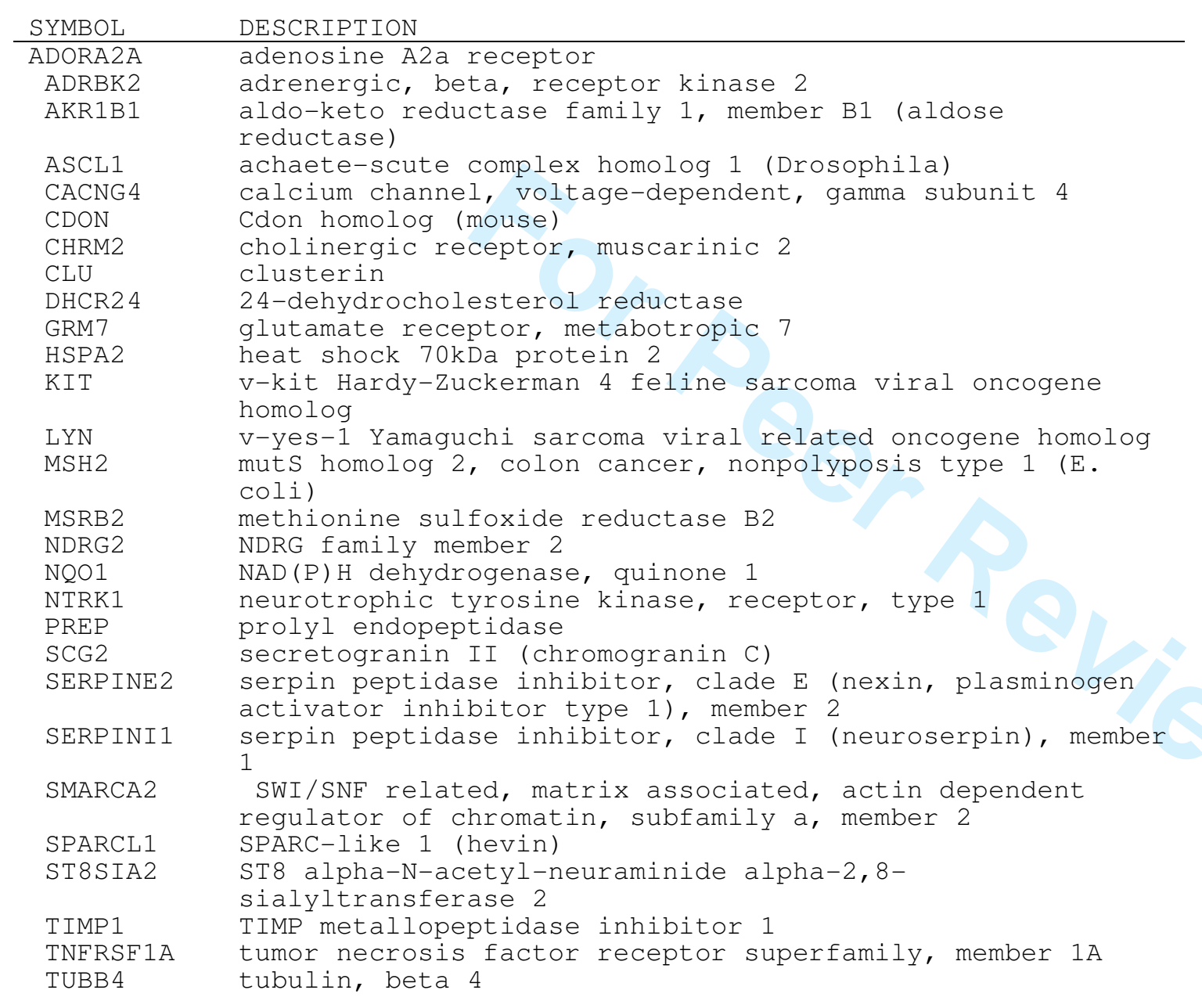

\section{Axonal Guidance Signaling}

\begin{tabular}{|c|c|c|c|}
\hline & - & paraquat & SOD1 (G93A) \\
\hline SYMBOL & DESCRIPTION & $\log 2 \mathrm{FC}$ & $\log 2 \mathrm{FC}$ \\
\hline BMP 7 & bone morphogenetic protein 7 & -0.517 & -2.050 \\
\hline
\end{tabular}




\begin{tabular}{|c|c|c|c|}
\hline DPYSL 5 & dihydropyrimidinase-like 5 & $-1,365$ & $-0,529$ \\
\hline EPHA6 & $\mathrm{EPH}$ receptor A6 & $-0,702$ & $-0,581$ \\
\hline NTRK1 & neurotrophic tyrosine kinase, receptor, type 1 & $-1,115$ & $-0,749$ \\
\hline PLXNA4 & plexin A4 & $-0,684$ & $-0,699$ \\
\hline SDC2 & syndecan 2 & $-0,908$ & $-1,229$ \\
\hline SEMA3D & $\begin{array}{l}\text { sema domain, immunoglobulin domain (Ig), short basic } \\
\text { domain, secreted, (semaphorin) 3D }\end{array}$ & 0,999 & 1,136 \\
\hline EMA6A & sema domain, transmembrane domain (TM), and cytoplasmic & $-1,131$ & \\
\hline
\end{tabular}

\section{Glycerolipid Metabolism}

\begin{tabular}{lll} 
SYMBOL & DESCRIPTION \\
\hline AKR1B1 & aldo-keto reductase family 1, member B1 (aldose reductase) \\
PPAP2B & phosphatidic acid phosphatase type 2B
\end{tabular}

GLB1L2 galactosidase, beta 1-like 2

\section{Glycosphingolipid Biosynthesis}

\begin{tabular}{ll} 
SYMBOL & DESCRIPTION \\
\hline GLB1L2 & galactosidase, beta 1-like 2 \\
ST8SIA2 & ST8 alpha-N-acetyl-neuraminide alpha-2, 8-sialyltransferase 2
\end{tabular}

\section{Genes related to neuritogenesis.}

\begin{tabular}{|c|c|c|c|}
\hline SYMBOL & DESCRIPTION & $\frac{\text { paraquat }}{\log 2 \mathrm{FC}}$ & $\frac{\operatorname{SoD} 1(\mathrm{G} 93 \mathrm{~A})}{\log 2 \mathrm{FC}}$ \\
\hline FEZ1 & fasciculation and elongation protein zeta 1 (zygin I) & & -2.047 \\
\hline ISL1 & ISL LIM homeobox 1 & -1.208 & \\
\hline FOXD1 & forkhead box D1 & & -1.373 \\
\hline FOXM1 & forkhead box M1 & -1.020 & \\
\hline FOXD 4L 3 & forkhead box D4-like 3 & 0,955 & 0,895 \\
\hline LHX9 & LIM homeobox 9 & -1.881 & 1.685 \\
\hline $\mathrm{LMO} 3$ & LIM domain only 3 (rhombotin-like 2) & -3.470 & -3.598 \\
\hline $\mathrm{LMO} 7$ & LIM domain 7 & $-0,553$ & $-0,581$ \\
\hline NEUROD1 & neurogenic differentiation 1 & -2.029 & \\
\hline NEUROG2 & neurogenin 2 & -2.631 & \\
\hline
\end{tabular}

\section{Supp. Table S8. Main Entrez Gene abbreviations used in the text}




\begin{tabular}{|c|c|c|}
\hline Gene Name & GeneID & Official Name \\
\hline ABLIM1 & 3983 & actin binding LIM protein 1 \\
\hline AKR1B1 & 231 & aldo-keto reductase family 1 , member B1 (aldose reductase) \\
\hline ASCL1 1 & 429 & achaete-scute complex homolog 1 (Drosophila) \\
\hline ATF3 & 467 & activating transcription factor 3 \\
\hline BIN1 & 274 & bridging integrator 1 \\
\hline BTG2 & 7832 & BTG family, member 2 \\
\hline CCNA2 & 890 & cyclin A2 \\
\hline CCNB1 & 891 & cyclin B1 \\
\hline CCNE2 & 9134 & cyclin E2 \\
\hline CDKN1A & 1026 & cyclin-dependent kinase inhibitor 1A (p21, Cip1) \\
\hline CDKN3 & 1033 & cyclin-dependent kinase inhibitor 3 \\
\hline CHN1 & 1123 & chimerin (chimaerin) 1 \\
\hline $\mathrm{CXCR} 4$ & 7852 & chemokine (C-X-C motif) receptor 4 \\
\hline ERBB3 & 2065 & v-erb-b2 erythroblastic leukemia viral oncogene homolog 3 (avian) \\
\hline GADD 45A & 1647 & growth arrest and DNA-damage-inducible, alpha \\
\hline GLB1L2 & 89944 & galactosidase, beta 1 -like 2 \\
\hline GNAO1 & 14681 & $\begin{array}{l}\text { guanine nucleotide binding protein (G protein), alpha activating activity } \\
\text { polypeptide } 0\end{array}$ \\
\hline HGF & 3082 & hepatocyte growth factor (hepapoietin A; scatter factor) \\
\hline KIF $1 \mathrm{~A}$ & 547 & kinesin family member $1 \mathrm{~A}$ \\
\hline LMO3 & 55885 & LIM domain only 3 (rhombotin-like 2) \\
\hline LRRK2 & 120892 & leucine-rich repeat kinase 2 \\
\hline MDM2 & 4193 & Mdm2 p53 binding protein homolog (mouse) \\
\hline NEUROG3 & 50674 & neurogenin 3 \\
\hline NTRK1 & 4914 & neurotrophic tyrosine kinase, receptor, type 1 \\
\hline NKX2. 2 & 4821 & NK2 homeobox 2 \\
\hline NRG1 & 3084 & neuregulin 1 \\
\hline PARK 7 & 11315 & Parkinson disease (autosomal recessive, early onset) 7 \\
\hline PAX 6 & 607108 & paired box 6 \\
\hline PINK1 & 65018 & PTEN induced putative kinase 1 \\
\hline
\end{tabular}




\begin{tabular}{|c|c|c|}
\hline PLXNA4 & 91584 & plexin A4 \\
\hline POLH & 5429 & polymerase (DNA directed), eta \\
\hline PPAP 2B & 8613 & phosphatidic acid phosphatase type 2B \\
\hline PPM1D & 8493 & protein phosphatase 1D magnesium-dependent, delta isoform \\
\hline RPRD1A & 55197 & regulation of nuclear pre-mRNA domain containing $1 \mathrm{~A}$ \\
\hline $\mathrm{SDC} 2$ & 6383 & syndecan 2 \\
\hline SEMA3A & 10371 & $\begin{array}{l}\text { sema domain, immunoglobulin domain (Ig), short basic domain, secreted, } \\
\text { (semaphorin) } 3 \mathrm{~A}\end{array}$ \\
\hline SESN1 & 27244 & sestrin 1 \\
\hline SESN2 & 83667 & sestrin 2 \\
\hline ST8SIA2 & 8128 & ST8 alpha-N-acetyl-neuraminide alpha-2,8-sialyltransferase 2 \\
\hline TP 53 INP 1 & 94241 & tumor protein p53 inducible nuclear protein 1 \\
\hline VSNL1 & 7447 & visinin-like 1 \\
\hline WASF 3 & 10810 & WAS protein family, member 3 \\
\hline
\end{tabular}




\section{Supp. Table S9. Oligonucleotide primers}

Nucleotide sequences of the primers employed for RT-PCR real time

Species: Homo sapiens

Gene ID Forward_Sequence (5'-3') $\quad$ Reverse_Sequence (5'-3') Product lenght (nt)

\begin{tabular}{|c|c|c|c|}
\hline ADAMTs1 & TTTGATAAATGTGGTGTTTGCG & TTTTGCACTAGTAACTGATCCTG & 75 \\
\hline AIFM2 & CGTCAACTCTGTGAAGCA & CATGGACAGGAGGAACG & 70
\end{tabular}

\begin{tabular}{|c|c|c|c|}
\hline APBA1 & CACGAGAAGATCGTCCAC & GGCTGGCATTGTCTTCA & 66 \\
\hline ASCL1 & GACTTTGGAAGCAGGGT & CAACGCCACTGACAAGAA & 62 \\
\hline
\end{tabular}

\begin{tabular}{|c|c|c|c|}
\hline CABLES1 & GGGTGCTGATGGGAAGACT & CAGGTTACGGAACTGGGAGA & 115 \\
\hline CHN1 & GTATGTAGGCATCTTTCATTCAGA & CAAAACACTCAGCATCTCTCTTT & 129
\end{tabular}

\begin{tabular}{|c|c|c|c|}
\hline CHN1 & GTATGTAGGCATCTTTCATTCAGA & CAAAACACTCAGCATCTCTCTTT & 129 \\
\hline CNTN4 & CTGTCAGCCATCAGTACAATAAT & AGCAAGTCCTTCAGATAACTTT & 78 \\
\hline CXCR4 & ATTGGGATCAGCATCGACTC & CAAACTCACACCCTTGCTTG & 61 \\
\hline EPHA6 & AAGGAGATTGATCCCTCAAGAA & CGCCCACTACAGACTTCTCC & 77 \\
\hline GAPDH & ACGGATTTGGTCGTATTGGG & TGATTTTGGAGGGATCTCGC & 231 \\
\hline
\end{tabular}

\begin{tabular}{|c|c|c|c|}
\hline GPM6B & CCTGGAGAACATCTGCAAC & GGCCACAATGAACAGGT & 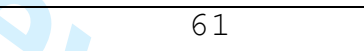 \\
\hline $\mathrm{HGF}$ & AGCATGTCCTCCTGCATCTC & TTGTATTTCTTCTTTTCCTTTGTCC & 78 \\
\hline ITGA9 & TGCTCTGGAAGATGGGC & GGTTCTTCTCAGCTTCGATAATTT & 63 \\
\hline $\mathrm{LMO3}$ & CTTTGCATGTCAGCTTTGTAAT & CCTTCCTCGTAGTCCGT & 96 \\
\hline NRP 2 & GGACCCCCAACTTGGATT & ATGGTTAAAAAGCGCAGGTC & 61 \\
\hline NTRK1 & GAGGCAATCGACTGCATCA & GTAGACCTCTGGTGGGC & 69 \\
\hline NUDT11 & TTCGGTTAGCATTGGGAGG & GCTTGTGGCACTGGAGAA & 74 \\
\hline SDC2 & GTCCTAGCAGCTGTCATT & TACACCAACAGCAGGATAAGAAA & 74 \\
\hline SEMA3A & GCGAAATGAAGAGCGAAAAG & TTTGTATGAACCCATGTTCCAC & 140 \\
\hline SLIT3 & CTTGTCTCCCTGTCCACCATA & CCTCTTCCTCAACCACTTGC & 90 \\
\hline SLITRK6 & TACGCAGTGGTTGGTGTTTT & TCCACAGCTTCATGTTGTCAT & 146 \\
\hline SMARCA2 & AAACCTGTAGTGAGCGATT & TCATCATCCGTCCCACTT & 80 \\
\hline TNIK & AGCTCAAAGGTTAAAGTTTCTATG & TTCCTCCAGATCGCACG & 71 \\
\hline
\end{tabular}




\begin{tabular}{|c|c|c|c|}
\hline VSNL1 & GTGATGGCAAGATCACCC & ATCACAGTGCCTACCATT & 73 \\
\hline WASF3 & CGAATGGGAATTCAACTGAAA & GTCATTCCCCACTGGCT & 75 \\
\hline ZNF521 & GCAGAATCATACAATGACCCA & AATCAATTCTCCTTGAGAGACT & 65 \\
\hline
\end{tabular}


Species: Mus musculus

\begin{tabular}{|c|c|c|c|}
\hline Gene ID & Forward_Sequence $\left(5^{\prime}-3^{\prime}\right)$ & Reverse_Sequence $\left(5^{\prime}-3^{\prime}\right)$ & $\begin{array}{c}\text { Product lenght } \\
(n t)\end{array}$ \\
\hline $\operatorname{cdc} 42$ & АСААСАААСАААТТСССАТСG & TTGCCCTGCAGTATCAAAAA & 114 \\
\hline $\operatorname{Cxcr} 4$ & TGGAACCGATCAGTGTGAGT & GGGCAGGAAGATCCTATTGA & 131 \\
\hline Fez1 & AAGGCATCTCCAACATCCTG & AGCATCTGCAGGTCTTCCAC & 136 \\
\hline $\operatorname{Hgf}$ & CACCCCTTGGGAGTATTGTG & GGGACATCAGTCTCATTCACAG & 66 \\
\hline Hprt 1 & TCCTCCTCAGACCGCTTTT & CCTGGTTCATCATCGCTAATC & 90 \\
\hline Nrp2 & CGAAGTGAGAAGCCAGCAA & GAGGGATAGTCCTGGGGGTA & 99 \\
\hline Ntrk1 & GGACCTCAACCGTTTCCTC & CCATACCAGCAGCCACCT & 131 \\
\hline Sema3a & GGGAAGAGCCCTTATGATCC & CCGCAGCAGTTCCAGAGTA & 79 \\
\hline Sept2 & CAGTGAAGAAGGGGTTCGAG & TCTGGGTAGAGATCAGTCAGGA & 103 \\
\hline Sept 7 & AGGGGATGTCGGTCAGTG & CAAGGTTCTTCGGTTGAGCTA & 87 \\
\hline Slit1 & AACGTGGCAGAGGTGCAA & GCAGGAACCGGACGAGAG & 93 \\
\hline slit2 & CTGTCATGGGCTGGCACT & TCCTCGTGATGTTATTTCCATTC & 89 \\
\hline slit3 & ACCGGTTCCAGTGCAAAG & TGCAAGTGCCGTTGTTCTT & 93 \\
\hline Wasf3 & CTGTGGCTGAGGCAAAGC & TGCACCTTTTTCAGTTGGATT & 106 \\
\hline
\end{tabular}


Figures for Referee 2

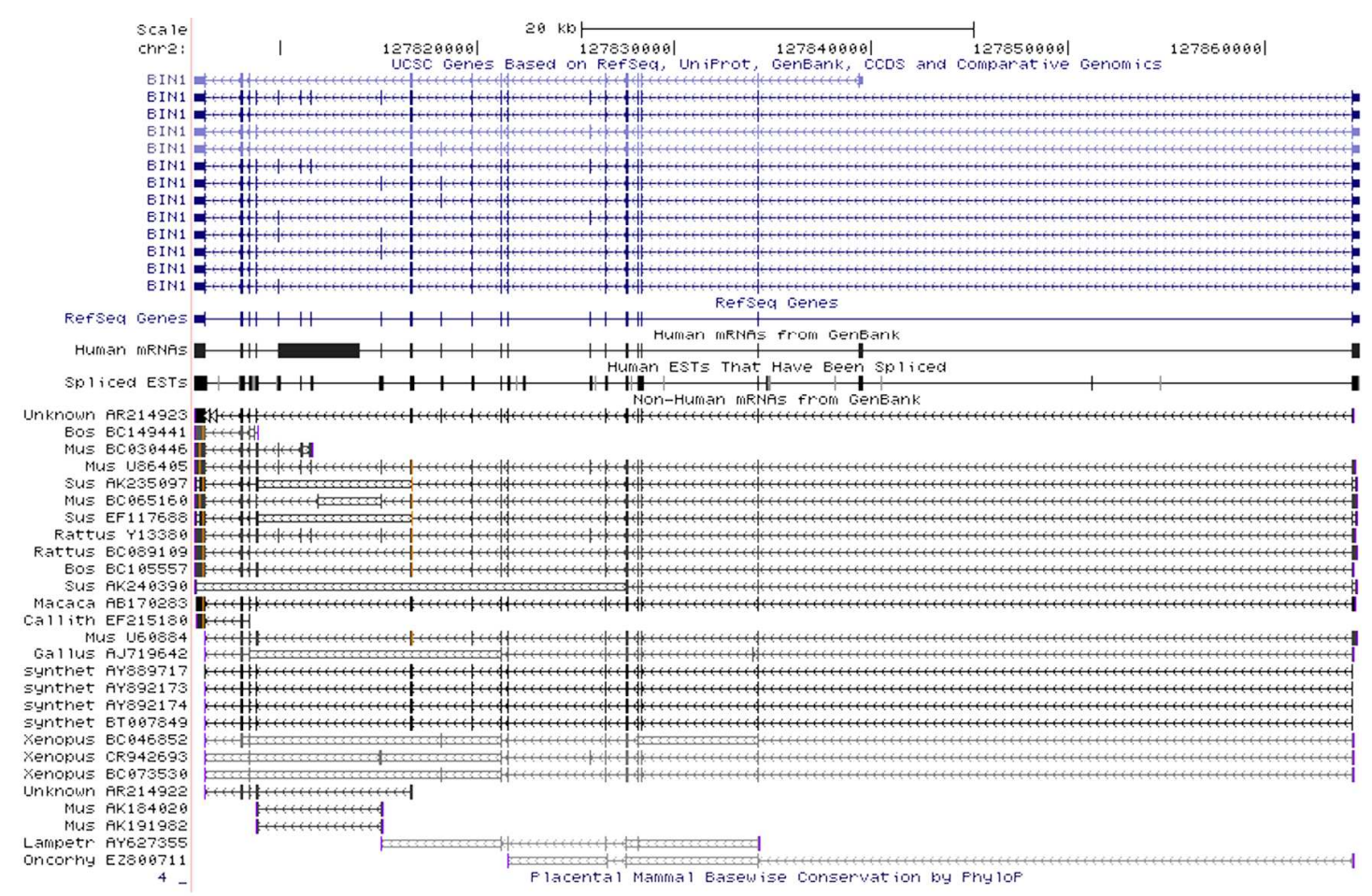

Figure R1. Comparison of the human and mouse BIN1 gene structure (UCSC Genome Browser). 
A

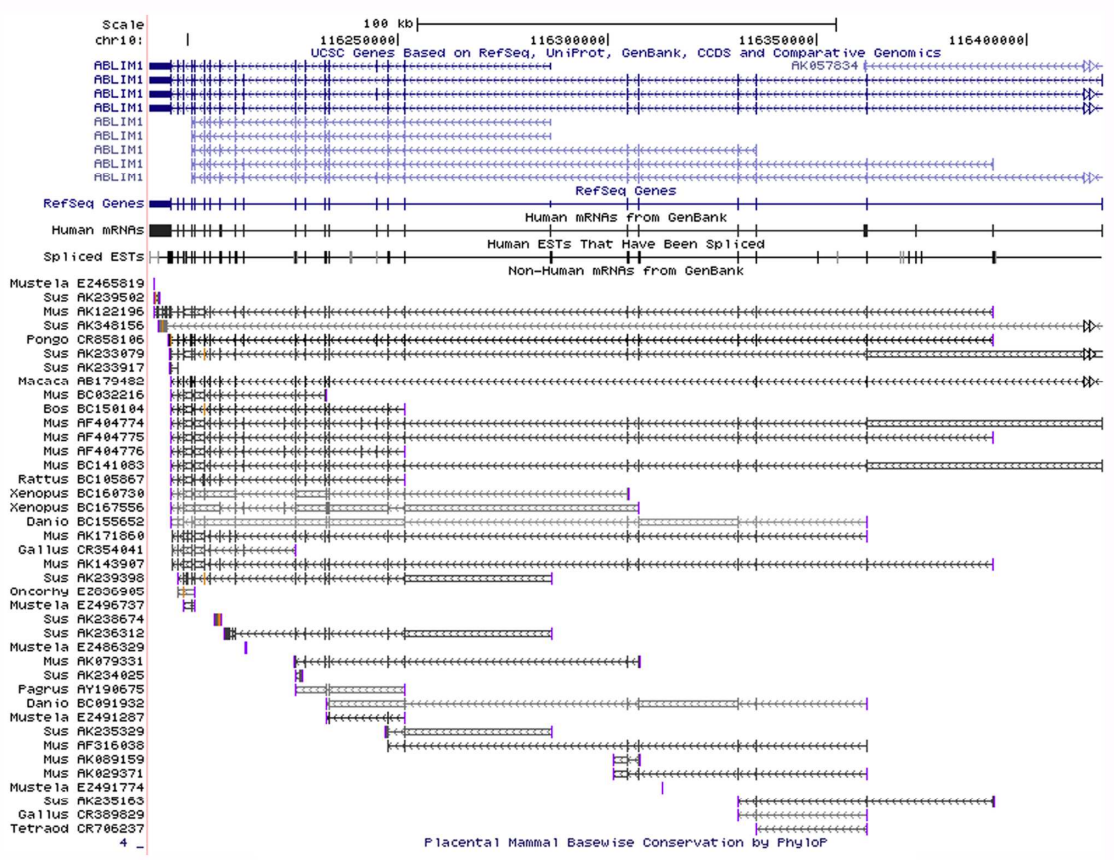

B

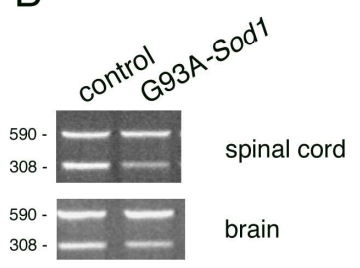

C

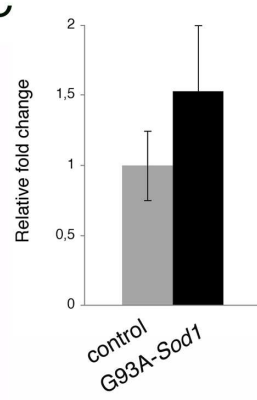

D



Figure R2

Figure R2. Analysis of the alternative first exon usage in the G93A-Sod1 mouse.

A. Comparison of the human and mouse ABLIM1 gene structure (UCSC Genome Browser).

B. RT-PCR analysis of the transcripts including the two putative first exons.

C. Quantitation of the PCR fragments. The bar graph represents the quantitation of the RT-PCR analysis for the long and the short Ablim1 mRNA variants. The first exon switch was normalized relative to that observed in the respective control (light grey bars). The dark grey bars show the average fold-change of the short mRNA variant transcribed from proximal promoter; error bars indicate the standard error.

D. Time course analysis of long Ablim transcript in the spinal cord of G93A-Sod1 mice during disease progression. Plotted is the ration of the long over the short mRNA variant normalized to that of age-matched non-transgenic control animals (opened circles) on different days from the pre-onset till the symptomatic stage (93-170 days). 